\title{
LA EDICIÓN (2006) DE LA CORRESPONDENCIA COROMINAS/MENÉNDEZ PIDAL ecdótica, bibliografía, umbral historiográfico
}

(1)

JosÉ PolO

catedrático universitario de Lengua Española

\begin{abstract}
A la memoria de Diego Catalán Menéndez-Pidal (1928-2008), insobornable gran maestro de hispanistas,

ya personaje histórico de entre «los últimos de Filipinas».
\end{abstract}

Epistolario Joan Coromines\&Ramón Menéndez Pidal, dispuesto para la imprenta por José Antonio Pascual y José Ignacio Pérez Pascual; Pròleg de Max Cahner; Fundació Pere Coromines, editat per Curial Edicions Catalanes, Barcelona, 2006, 392 págs.

$$
\frac{\text { PRIMERA PARTE }}{\text { INTRODUCCIÓN }}
$$

\section{Preliminares}

$0-1$

Articulo el presente trabajo, analógicamente a lo que suele decirse con respecto a la estructura silábica (intensión, tensión, distensión), en tres secciones de amplitud creciente, a saber: la primera, vista en conjunto como una introducción generosa; la segunda, nuclear: además de los imprescindibles datos bio-bibliográficos acerca de un personaje científico cuya presencia en el aparato crítico se imponía (pero no se encuentra), 
aparecerán determinados textos epistolares complementarios de los que se hallan en el volumen objeto de atención; finalmente, en la tercera sección (última entrega), ya con observaciones sumarias, a veces telegráficas, recorreré el texto de esas cartas para las menudencias de todo tipo de segura utilidad pensando en una necesaria nueva edición, cual suele decirse, «corregida y aumentada» (pues alguna nueva carta podrá sorprendernos): la trascendencia de los dos grandes actores y de las consiguientes notables realidades humanas y científicas visibles en tal epistolario obligan a ello.

\section{$0-2$}

Añado finalmente que no es esta la primera vez en que me ocupo de materia epistolar: véase «Sobre la correspondencia Cuervo-Menéndez Pidal», en Revista de Filología Española, LXXXI/2001, págs. 165-183 y 273-316. También, en serie, no obstante su apariencia, apenas iniciada y pendiente de nuevo medio hemerográfico para su continuación y conclusión: «Correspondencia científica (1927-1952) Dámaso Alonso/ Amado Alonso», en Cauce. Revista de Filología y su Didáctica: 1=18-19/1995-1996, páginas 165-180; 2=20-21/1997-1998, págs. 247-258; 3=22-23/1999-2000, págs. 437-452; 4=27/2004, págs. $341-348 ; 5=27 / 2007$, págs. $357-383$.

1

El denso volumen (aleccionador y moralmente ejemplar, translúcido en virtudes humanas, en saberes técnicos y en «sufrimiento filológico»), con trabado aparato crítico, contiene en primer lugar el susodicho prólogo en catalán (págs. 5-7; su autor es el President de la mencionada fundación); viene a continuación un extenso y obligado Prefacio (once epígrafes, págs. 9-68): «El Diccionario crítico etimológico de la lengua castellana de Joan Coromines [J. Corominas: así en su «paradigmática» manifestación en Editorial Gredos]: una aventura intelectual y vital»; en su parte final, se encuentran, fuera ya de la estructura «epigráfica», los rótulos «Normas de edición» (págs. 64-65) y «Bibliografía» (págs. 66-68); dentro de esta, «Epistolarios» (pág. 66) y «Otras obras de referencia» (todas ellas, oportunas; págs. 66-68). La correspondencia queda anunciada, mediante portadilla, página implícita 69 , y los textos epistolares (97: entre finales de junio de 1929 y 17 de febrero de 1964) comprenden las páginas 71-370. Enseguida, nueva portadilla (pág. impl. 371) con la nominación «Índices», subdivididos estos en «Índice de nombres» (autores, títulos de obras, etc.), págs. 373-387, e «Índice», págs. 389-392, equivalente a un índice general, en el que aparece la sucesión de todas esas cartas con sus datos de procedencia, fecha, etc.

\section{2}

La primera carta es la del esforzado, por no decir heroico, romanista etimólogo, casi permanentemente, podríamos decir, «en estado de necesidad»: bibliográfica y, en ocasiones, metodológica, además de la humana y profesional de alguien que lucha a brazo partido para abrirse camino con la vista siempre puesta en llevar a feliz término, entre ellas, las consabidas imponentes obras (sus dos diccionarios etimológicos: catalán y «castellano»); el último texto epistolar, del maestro por antonomasia, también en generosidad y señorío, 
como se va percibiendo a lo largo de la correspondencia. Por el hecho de hallarse tal obra en una determinada colección (Textos i Estudis, en la que preceden, hasta ese momento, diez volúmenes epistolares, todos ellos con nuestro personaje científico hispano-catalán como centro, empresa en verdad admirable), es perfectamente coherente que el primer nombre del título de la obra corresponda, claro está, a Corominas.

3

En cambio — y he aquí la primera crítica ponderada—, no es «filológicamente» correcto, por más que se halle en una colección dedicada a /Joan Coromines/, que aparezca esta forma onomástica en el título del volumen y, coherentemente repetido, en la cabecera de las páginas impares, además de preceder a cada una de las cartas al indicarse el dato de remitente y destinatario; y tal proceder es incluso «antifilológico» sencillamente porque la persona que escribe a Menéndez Pidal no es Joan Coromines, sino, como se ve palpablemente al final de cada una de sus cartas, y ya conocíamos por determinadas publicaciones suyas de lingüística española en la época abarcada, Juan Corominas. Trasladémonos a la modalidad literaria de la crítica textual o ecdótica (concepto para mí aplicable igualmente a textos no literarios) y preguntémonos si algún estudioso con fundamento se habría atrevido a cambiar la «letra onomástica» de un autor - literario, digo - en la edición de alguna de sus obras, si habría mezclado «sincronías onomástico-antroponímicas»; no se puede operar extemporáneamente/anacrónicamente, «des-sincronizando» una determinada realidad onomástica; podríamos hablar de «anacronismo antroponímico». De otro modo: durante esa larga «sincronía epistolar», dentro del ámbito respectivo de la filología española, no se han dado, a su vez, «subsincronías» o cortes menores, sino una línea sostenida Juan Corominas en la proyección de su alteridad hacia el maestro Ramón Menéndez Pidal, vale decir, en esta peripecia, hacia la lingüística española. La consecuencia para mí es clara: no se debe permitir la entrada de otro código (sea filológico o no) en el ya asentado en ese largo proceso comunicativo confirmatorio del «sintagma onomástico» Juan Corominas; el responsable de una edición no puede permitir, insisto, la «neutralización» del criterio filológico por otro, «exógeno» en grado variable. Con otras palabras: la variante Juan Corominas puede instalarse, con naturalidad plena, en una colección dedicada a Joan Coromines y convivir con la forma hoy día canónica visto el conjunto: cada momento histórico tiene sus propias exigencias y nuestra obligación como filólogos es, entre otras cosas, no distorsionar tal realidad.

4

a) En cuanto a los aspectos materiales de la edición, dejando ahora de lado las erratas y otros hechos en línea parecida (que comienzo a mostrar en la presente entrega y continuará en la siguiente), lamento señalar que se trata, como en la inmensa mayoría de los libros que hoy día se publican (y no solo 
en España), de una edición más bien tosca, muy poco cuidada. Si los autores no adquirimos una muy sólida formación tipográfica, con sus aledaños (existen, además de la particular experiencia de un investigador dado, excelentes y variados manuales, incluyendo algunos antiguos ya clásicos), el resultado es conocido de antemano, pues hoy día se ha convertido en un hecho singular encontrar, en los talleres y en las editoriales, a pesar de las mencionadas instructivas obras, profesionales de la tipografía y tareas próximas a ello con la preparación que antaño veíamos como un hecho natural (¿habrá en toda España más de doce unidades sumando ambos frentes?). Vuelvo a lo concreto: no se observa el menor esfuerzo por corregir las deficiencias de los programas informáticos en materia de tipografía: números arábigos con la altura de la «caja alta»; otras veces, en las fechas, aparece, para el mes, un romano encajonado y reducido con respecto a la altura de los arábigos entre los cuales se halla; corchetes que, con su desmedida altura, distorsionan el «paisaje letrado»; ruidosas versales que debieran ser versalitas o, mal menor, seudoversalitas.

b) Por otra parte, han operado con la injustificada moda de colocar un punto tras el número de respuesta en las notas (por supuesto, con arábigos que hacen más bulto que la propia línea textual): compárese la elegancia de la solución clásica (numeritos ligeramente volados y, naturalmente, sin punto «escolar»), la adoptada, por ejemplo, en los libros de la Editorial Gredos hasta hace unos años, en su mejor época.

c) Abundantes finales de línea, con su correlato en el comienzo de la línea siguiente, mal resueltos ortotipográficamente, ayunos de soluciones fundamentadas en una mínima cultura tipográfica y de técnica de la presentación de los trabajos escritos. Son centenares los casos mal resueltos (y no me detendré en señalarlos, salvo que observe alguna partición que dé como resultado una forma malsonante y en algún otro caso como simple recordatorio de la necesidad de revisar todo el volumen en una próxima edición, ya asentada, definitiva); tampoco lo haré cuando, tratándose de ofrecer una paginación - por ejemplo, /341-345/- queda el primer sintagma numérico y el guión [así, con acento, como, antiacadémicamente, debe ser] a final de línea, situación en la que debe repetirse tal guión al comienzo de la línea siguiente: geminación visualmente discontinua de ese guión internumeral/internumérico. Aplíquese a estructuras onomásticas personales compuestas y a otros casos asimilables al esquema que he puesto de relieve.

d) En las llamadas de nota, aunque existen opiniones diversas, el criterio preferible es colocarlas antes de los signos de puntuación (coma, punto y coma, dos puntos, punto) y después tratándose de rayas de inciso y de paréntesis (la casuística es muy amplia y no puedo detenerme en determinadas explicaciones técnicas, incluyendo las de las virtuales justificables excepciones y la de los puntos suspensivos y algún otro signo o incluso símbolo); compárese en este asunto la sensatez de la práctica en la revista francesa Criticón. Tampoco es recomendable en español valerse de /p., pp., s., ss./, por muy extendido que se halle tal uso, en lugar de /pág., págs., sig., sigs./ (no puedo extenderme, 
adelantándome a consabidos argumentos en sentido contrario, en la explicación, más allá de lo evidente, de su irrecusable justificación técnica). Lo mismo: preferible /y otros/ a /et alii/ (por ejemplo, pág. 68). Dentro de una práctica nada rara, se dan, igualmente, otros casos necesitados de leve admonición.

e) Mal configurados (desequilibrados hacia arriba) aparecen por doquier los antilambdas/diples o signos de origen/derivación de formas. Añádase la vulgaridad de - con el blanco de cortesía (mejor reduciéndolo algo) antes de cada unidad epistolar, comience esta en página par o impar (inobjetable)-, la vulgaridad, decía, de colocar el folio explicativo (cabecera o cornisa) EPISTOLARIO (pares) O JOAN COROMINES \& RAMÓN MENÉNDEZ PIDAL (impares; así: con un incorrecto exceso de blanco alrededor del consabido signo universal), el cual folio explicativo en página inicial de carta mata -0 , al menos, afeaese canónico blanco de cortesía.

5

Todavía dentro del espacio relativo a los aspectos materiales, pero en otro sentido, me veo obligado a señalar la presencia de un número excesivo de «disonancias gráficas» (diversos hechos de interpunción/puntuación/puntuarios, ortotipográficos, «erráticos/erróticos», etc.) si tenemos en cuenta que son dos los autores responsables de la edición (teóricamente, sendas lecturas de pruebas siquiera una vez) y, además, habría resultado escasamente tolerable la ausencia de un tercer lector (ahora, de la propia editorial) dada la complejidad y delicadeza del material con el que se ha trabajado. Particularmente en la siguiente entrega iré mostrando tales «erraticidades», así como otras menudencias, todo ello con los comentarios, sucintos, respectivos para que, en una imprescindible nueva salida pública, podamos contar con la presentación de un texto a la altura de los dos grandes actores de este hermoso y aleccionador diálogo. En otro ámbito, podemos leer (pág. 64): «Adaptamos el texto a las normas actuales (acentuación, empleo de mayúsculas y minúsculas, puntuación); como es lógico, corregimos algunas erratas mecanográficas, sin mayor notación (del tipo mestra por muestra en la carta 63)». Ello me dará libertad para actuar en materia de puntuación, la más sintagmáticamente compleja, con diversas sugerencias de posible mejora y en ocasiones en un nivel que va más allá de la mera sugerencia; y lo haré, sin espíritu de completitud, tanto en el texto de los responsables de la edición como en el de las propias cartas. Alguien podrá preguntarse si es una actuación técnica adecuada ajustar la puntuación a nuestra sincronía de investigadores o si no resultaría preferible o no intervenir en absoluto o hacerlo, según los casos, mediante las interpolaciones esperables o en nota a pie de página para señalar que un signo puntuario falta o sobra. Esta es una cuestión nada mecánica que no puede despacharse ni en cinco líneas ni en unas cuantas más porque, aparte el hecho en sí (mantenimiento o no del «género textual» del original, nivel de excelencia puntuaria o no en dichos textos, etc.), entra en juego, junto a circunstancias y perspectivas múltiples en las que no puedo detenerme, el tipo de lector al que va dirigido ese material (modalidad 
de edición) y, por supuesto, el grado de conocimiento básico y finamente estilístico de los complejos mecanismos de la puntuación en el estudioso que vaya a intervenir en dicho texto. Lo diré de otro modo: yo transmitiría una u otra recomendación, y hasta prescripción, según a quién fuera dirigida... En fin, me abstengo de explicar qué haría en tal situación (compárese, no obstante, el amago de línea metodológica anunciada en el párrafo que antecede a v); simplemente, con base en la mencionada libertad a partir de las palabras que he citado líneas atrás, comentaré en los lugares oportunos las unidades o los pasajes que inciten a ello (siempre, cual he señalado, con un carácter alejado de lo exhaustivo).

\section{6}

Finalmente, es muy justo citar el último párrafo (pág. 65) del Prefacio: «No queremos terminar esta breve nota introductoria [se refieren, cabe pensar, a "Normas de edición" (págs. 64-65), no al conjunto, extenso, de dicho texto preliminar] sin dar las gracias a quienes nos han ayudado en nuestra tarea, de un modo particular a Diego Catalán, Mariano de la Campa, Max Cahner, Cleofé Tato, Josep Ferrer y Joan Pujadas». Añado, por mi parte, que el hecho de haber sido responsable de la biblioteca y del archivo de la Fundación Ramón Menéndez Pidal (a propuesta de Diego Catalán, a quien con profunda admiración y respeto a su memoria he dedicado el presente «ensayo metodológico») entre marzo del 2004 y julio del 2010 me ha permitido un conocimiento que, sin la menor duda, ha resultado provechoso a la hora de concebir y elaborar el presente trabajo, paralelo, en cierto modo, aunque varíe la materia prima, del que publiqué, en torno a un maestro de maestros universal, en el Boletín de la Real Academia Española, XCII-306/2012, págs. 101-122: «La última bibliografía lapesiana (2008)».

\section{Bibliografía introductoria mínima}

A

1. Epistolarios de corte histórico, político y, sobre todo, literario se han publicado unos cuantos en los últimos años. También han aparecido, además de los aclaratorios textos «normativos» preliminares de dichos volúmenes, no pocos trabajos - artículos y textos periodísticos principalmente- relacionados con los aspectos éticos e historiográficos de dicho material. No es momento de ocupar páginas con las fichas de las unidades que yo poseo; simplemente, cual ilustración viva y a manera de espécimen, remito a las cinco primeras entregas (dedicadas a cuestiones preliminares metodológicas, etc.) de mi serie «Correspondencia científica (1927-1952) Dámaso Alonso/Amado Alonso» (véase atrás 1/0-2). La publicación de nada menos que cinco entregas, con la idea de preparar el terreno (perspectiva ética, historiográfica, textual, etc.), es indicativa de la importancia que yo le asigno a este género virtualmente científico. Independientemente de que en el futuro me decida a reunir en un volumen 
dicho conjunto de páginas preliminares de carácter general (si alguna editorial me lo solicita), me falta, justamente, editar todo el material, lingüístico y literario, de la mencionada correspondencia alonsiana; dada la complejidad técnica de tal labor, debería hacerlo en primer lugar en varios números de alguna publicación periódica (si se me comunica el interés en ello) aunque, una vez conclusa tal serie, quepa reunir dichos textos, con su aparato crítico e igual que en el caso anterior, en un volumen con sus siempre aconsejables índices auxiliares.

2. Puede completarse la información anterior en varios capítulos de mi libro La imagen sin par de Rafael Lapesa (1908-2001) a través de mi archivo, Biblioteca Nueva, Madrid y Editorial Universidad de Granada, 2015. Los capítulos epistolares aludidos son los siguientes: IX, «Salvador Fernández Ramírez (1896-1983), otro hito de amistad y de ciencia»; XII, «Observaciones a la octava edición (1980)»; XIII, «La novena (1981)»; XIV, «El magisterio de don Rafael Lapesa hacia mi persona (a través de la correspondencia)». Ya mucho antes, dentro de una serie que duró cinco años (1971-1976), «El español familiar y zonas afines (ensayo bibliográfico)», en revista bimestral madrileña ahora inexistente, Yelmo. La revista del profesor de español, había publicado «Notas epistolares a El español coloquial de Beinhauer», 23/1975, págs. 47-49; 24/1975, págs. 44-46; 25/1975, págs. 46-48; 26/1975 (diciembre)-1976 (enero), págs. 45-47; 27/1976, págs. 47-49. Precedía como entorno de esas cinco unidades «El español coloquial y Werner Beinhauer», 22/1975, págs. 47-48. Podrá resultar igualmente útil en algunos aspectos una obra también de mi autoría en Biblioteca Nueva y Ediciones de la Universidad Autónoma de Madrid (2012), a saber: Entorno del universo normativo de Eugenio Coseriu. Cuaderno de bitácora. Finalmente, para determinados hechos normativo-estilísticos no alejados de los señalados en el presente trabajo, no resultará inoportuno consultar mi extenso comentario, en tres partes, «Notas de carácter metodológico, bibliográfico, ortotipográfico y de técnica del trabajo científico alrededor de dos importantes obras "lingüístico-discursivas" en el entorno de Coseriu», en esta misma revista, Analecta Malacitana, XXXIV-2/2011, págs. 599-633; XXXVI/1-2/2013, págs. 349-392; XXXVII/1-2/2014, págs. 331-390.

B

3. GómEZ-TEN, Robert, «L'Epistolari de Joan Coromines: apunts d'història de la llengua per carta», en Estudis Romànics, XXX/2008, págs. 281-282. Da cuenta de los diez primeros volúmenes (o sea, de los que preceden al de nuestro centro de interés) de esa colección.

4. Pérez Pascual, José Ignacio, «Joan Coromines y el Diccionario crítico etimológico castellano [e hispánico]», en Zeitschrift für Katalanistik. Revista d'Estudis Catalans, 20/2007, págs. 83-100. Por su fecha, no pudo ser recogido en la bibliografía del Prefacio junto a otros meritorios trabajos del autor; prefiero ficharlo aquí para no detenerme, cuando me ocupe de dicha parte preliminar del volumen, con asuntos bibliográficos, siempre engorrosos y, en ocasiones, ilímites. 
5-6. En cuanto a reseñas a la obra que ocupa nuestra atención, no he llevado a cabo investigación alguna; simplemente, conozco dos: 1) Javier PRESÁn, en Revista de Filología Española, LXXXVII-2/2007, págs. 405-408; 2) Rosalía Cotelo García, en Dicenda.Cuadernos de Filología Hispánica, 26/2008, págs. 365-368. Se trata de dos textos que, no obstante su brevedad, sitúan adecuadamente en su entorno esta correspondencia trascendental a la vez que, muy justamente, ponen de relieve los aspectos técnicos positivos de la edición. Cabe, sin embargo, sin intentar quitarle mérito a tan compleja tarea, relativizarla, pues - ya se irá viendo - no se trata de un volumen «magnificamente editado [cursiva mía] y anotado [también habrá que observar una cierta falta de orientación ante la presencia de determinados nombres]» (pág. 405); tampoco, «La otra razón de porqué [por qué] leer este Epistolario es su excelente edición [...; cursiva mía]» (pág. 367).

\section{$\mathrm{C}$}

7. De Marco, Barbara, «"Romance ha de ser...”. The Correspondence of Yakov Malkiel and María Rosa Lida, 1943-1948», en Romance Philology, 59/2005, págs. 1-101; precede, no obstante, sin foliar una virtual página cero con la reproducción facsimilar de sendos textos epistolares de sus protagonistas con los datos de su procedencia ya en tipografía. La introducción abarca las páginas 1-5; los textos, 5-63; «Notes to correspondence», 64-92; «Appendix 1[...]», 92-96; «Appendix 2[...]», 96-97; «Appendix 3[...]», 97-99; «Appendix 4[...]», 99-101. Presento esta ficha cual mero recordatorio de diversos volúmenes de correspondencia dentro de la lingüística general y de la románica susceptibles de ser tenidos en cuenta como parte de una ambientación amplia en este terreno.

8. Juliá-MunÉ, Joan, «Francesc de Borja Moll i la lingüística nord-americana i hispánica a la llum dels epistolaris Mollians», en Llengua\&Literatura. Revista anual de la Societat Catalana de Llengua i Literatura (filial de l'Institut d'Estudis Catalans), 18/2007, págs. 135-231. Trabajo de mucho interés, con textos, aparte de los del Moll, de C. H. Grandgent, Menéndez Pidal, Tomás Navarro, Dámaso Alonso... y múltiples referencias de proyección historiográfica, además de una muy rica e instructiva bibliografía (págs. 225-231).

9. Cortés Carreres, Santi y Vicent García Perales (Introducción, selección y notas de; Presentación de José Jesús de Bustos Tovar; Epílogo de David Heap), La historia interna del Atlas Lingüístico de la Península Ibérica (ALPI). Correspondencia (1910-1976), Universitat de València, 2009, 514 págs. Impresionante volumen de trascendencia científica suma. Entre mis proyectos se halla el de realizar un artículo-reseña amplio (en este momento, no sé si en una sola unidad o con más de una entrega), dado el enorme aprecio científico y la importancia historiográfica —no es necesario dar nombres: resultaría ofensivo-que me inspira obra tan necesaria y oportuna. Espero que no me falten las fuerzas. Conozco la excelente reseña de José Ignacio Pérez Pascual en Revista de Filología Española, XCI-2/2011, págs. 348-354. 
10. Alonso Montero, Xesús, «Veintiséis cartas inéditas de Tomás Navarro Tomás a Aníbal Otero (1933-1936), obrantes en la causa contra el lingüista gallego y aportadas por su madre en el Consejo de Guerra del 5 de marzo de 1937 (Vigo)», en Hesperia, XIII-1/2010, págs. 5-47. ¿Qué humildad, profesionalidad y dignidad la de Aníbal Otero! ¡Qué elegancia espiritual la de Tomás Navarro! ¡Qué tristeza profunda y dolorida por la miseria humana...!

\section{Periferia: índice de nombres (373-387) y otras menudencias}

0

En su momento, cuando me detenga en los propios textos epistolares, podré señalar si se hallan presentes algunos nombres no recogidos en este índice (adelanto ya una respuesta afirmativa) o si faltan remisiones a otras páginas en diferentes autores (lo mismo). No se dice nada acerca de si en tal índice entran los copiosos nombres de las fichas bibliográficas que aparecen en las notas; comprendo perfectamente que no hayan sido tenidos en cuenta, aunque, si con un recomendable esfuerzo ¿ciclópeo? (por parte de personas, de algún programa informático, de ambos frentes) se hubiera llevado a cabo, habría resultado de enorme utilidad. De todos modos, ateniéndome a la esporádica atención que he prestado a este asunto, he señalado, como simple llamada de atención, varios casos de ausencia onomástica directa de personas del cuerpo del texto, pero la impresión que he sacado va en la línea de que probablemente faltan algunos más. En general, por las calas realizadas en este sentido, observo las susodichas deficiencias por ausencia de nombres: en unos casos (me refiero a situaciones no directamente bibliográficas) se tienen en cuenta las notas a pie de página y en otros no; la lista de tales desajustes puede que no sea pequeña. Otrosí: puesto que el número de páginas en esta sección del volumen no es grande y, además, tal ausencia la he ubicado en el sintagma del propio epígrafe, no la señalaré, la página, ya para cada una de las observaciones (erratas, etc.) que pondré a la vista del lector. Tal como hice notar en I-3, los finales de línea se hallan con relativa frecuencia mal configurados, pero, ya lo insinué, no voy a consignarlos, salvo en exiguo número, pues me vería obligado a explicar todas y cada una de las situaciones y ello ocuparía muchas páginas. Aquí, en este índice, al hallarse materializado en doble columna, las posibilidades de administrar el espacio son casi nulas. Baste lo dicho.

1) Mejor que limitarse a dar solo la primera página, de entre varias, que afecta a un tema es hacerlo señalando todas ellas. Así, la referencia al ALPI no debe remitir exclusivamente a la página 242, sino también a la siguiente: 242-243.

2) Dado que en su lugar (pág. 236) no se identificó a /Coleman/, se entiende que solo aparezca registrado por tal apellido sin el nombre de pila (para la segunda entrega intentaré localizar los irresueltos datos bibliográficos de un trabajo de dicho autor). Algo parecido con /Séller/. 
3) También en su momento podré confirmar si en este índice faltan las entradas /Förstemann/ y /Keller/ (sin extenderme ahora en complementos nominales).

4) Errata obvia en /Hernándo/. En otra sección (más adelante, VI) mostraré que no se trata de Teófilo Hernando, sino de alguien completamente alejado del entorno de esta persona.

5) Errata igualmente en /Leven/, que es, tal como aparece correctamente en sus lugares, /Levene/. Por otra parte, siendo inobjetable la presentación /93, 94, 95/, resulta más ágil /93-95/ para casos como este de páginas sucesivas.

6) Faltan /Martínez Salazar/ y /Parker/, con presencia ambos en pág. 236.

7) Errata inmediatamente perceptible en /Salvador, Gregori/.

8) Errata, ya no tan cristalina, o error por la proximidad gráfica en la escritura manual rápida, en /Weitscheck, María/: es /Woitscheck/, que, según documentos varios examinados, convive con su variante /Woitschek/, aunque, por los tales documentos, la primera, /ck/, es en este caso la genuina. De otro lado, aparece hispanizado el nombre de pila (práctica habitual en filólogos de esa época) tanto aquí como en pág. 369 (texto epistolar), cosa perfectamente defendible, pues es lo que se observa en la carta número 96 (compárese atrás, I-3, lo que defiendo con respecto a Coromines/Corominas); en cambio, en la página siguiente, 370, en nota, figura el nombre original, /Maria/, igualmente, claro está, inobjetable. Dejo como reflexión para una edición posterior si conviene uniformar y, en todo caso, si resultaría oportuno aclarar en nota una u otra de las soluciones.

\section{EI prefacio (9-68)}

\section{0}

El número que antecederá al comentario es el de la página. Las recomendaciones que hago son fruto maduro de una muy larga e intensa experiencia, visible en dos libros míos y en unos cuantos artículos (no puedo detenerme en las fichas correspondientes; no obstante, parte de esta información la he presentado atrás, II-2). Para evitar convertir dichos comentarios en una extensa monografía, me abstengo, en general, de dar las razones técnicas, en ocasiones nada breves, de mis propuestas; cuando las doy, lo hago en forma concisa.

10) Mejor criterio que /en aquest respecte. (Joan Coromines\&Josep Pla, pp. 39-40)/ es eliminar el punto tras /respecte/ y situarlo en el final absoluto, al cerrar el paréntesis. Por supuesto, aplíquese a cualquier otro caso del volumen (por ejemplo, págs. $25 \mathrm{y}$, dos casos, 62). Una situación con algún parecido con esta (pág. 27, nota 11) se halla perfectamente resuelta.

11) En la nota 2, llama la atención la expresión /trata que se especialicen en algún campo/; cabe pensar en el sintagma /trata de que..., 'intenta que': ¿nueva errata, analogía/ «anomalía» sintáctica?

13) $\mathbf{a}=$ No conviene utilizar el sistema de rayas de inciso si con la de cierre acaba la frase; sí en medio de ella. En nuestro caso, /del léxico catalán 
—el de los nombres de lugar de una manera particular-./, la solución se halla en valerse de los dos puntos o en colocar tal sintagma entre paréntesis, no «ruidoso» en ese espacio textual. $\mathbf{b}=$ La correlación /tanto...como/ no debe ser cortada por una coma, error muy extendido. Así que sobra la coma tras la voz/francesa/ en/Como romanista, intentó formar a los alumnos con sus solas fuerzas, que eran las que permitían explicar tanto Historia de la lengua francesa, como Gramática histórica del francés antiguo, Occitano y Lingüística románica/. $\mathbf{c}=$ No debe cortarse una palabra al final de línea provocando que la línea siguiente comience con un elemento de palabra homófono de una determinada unidad léxica: /escri-tos/. d=Hace muchos años que hablé de la «coma hiperbática», muy conveniente, cuando menos, en /Aprovechando precisamente esos períodos[,] empezó a recoger la toponimia viva - y con ella la antroponimia-, [coma más bien inoportuna] con una técnica simple y eficaz [...]/.

14) Nos las habemos con varios casos de «superposición repetitiva/iterativa/ ecoica» al comienzo o al final de línea: /la-la, en es-en es, de-de/; grados menos intensos o explícitos aquí mismo: /tes-te-tas, es-en/; además, corte no óptimo (pues no conviene que la línea siguiente se inicie con /ch, 11, r-rr/ no léxicos, segmentos de palabra): /colabo-radores/. Así, pues, página bien servida...

15) Se halla muy extendido el uso de coma delante de $/ y /$ entendiendo que ha habido un cambio en la dirección lineal semántica en el conjunto de la frase; el contraste semántico viene ya dado semántico-sintácticamente. En consonancia con lo que acabo de señalar, yo recomendaría prescindir de la coma en /Llegó a la Argentina a enseñar Gramática en la recién creada Universidad de Cuyo, y allí comenzó su diccionario etimológico castellano/. Con mucho relieve, habría cabido el punto y coma; y sin la conjunción /y/, a manera de consecuencia o similar, habría podido entrar, con naturalidad plena, el signo dos puntos.

20) Algo convendría haber hecho para evitar que en la palabra /desarrollan/ el corte hubiera colocado en la línea siguiente /rrollan/; tampoco habría resultado solución aceptable ver iniciada tal línea siguiente con/llan/. En casos como este debería buscarse evitar el corte o, mal menor, partir /de-sarrollar/.

21) A pesar de la omisión del primer apellido por parte de su autor (pero no de la inicial /S./=Sánchez), mejor que /Martín Ruipérez/ será /Martín S. Ruipérez/ o incluso /Martín Sánchez Ruipérez/ si, dentro de un mismo espacio temporal, también aparece esta variante. Compárese /Francisco Rodríguez Adrados, Francisco R. Adrados/, ambas formas registradas.

21-22) No es buena solución, cuando nos valemos de las rayas de inciso, iniciarlas en el extremo de la última línea de una página y acabarlas en la primera línea de la página siguiente: se produce una inconveniente disrupción o discontinuidad de lo que debiera ser una sola unidad visual como representación de la sola estructura sintáctica.

22) Corominas le escribe a Menéndez Pidal, pero no se cita desde la mayúscula de un comienzo de frase, sino, con minúscula, desde dentro de ella; en tales casos, salvo en situaciones en las que se enlaza de modo natural el discurso narrativo del que cita con su continuación en el texto citado, se impone 
comenzar con puntos suspensivos encorchetados y luego proseguir. Habría convenido que fuera /como él mismo escribía a Menéndez Pidal: «[...] tengo plena conciencia de que el difícil empeño en que estoy metido me obliga a abordar problemas sumamente espinosos y a veces insolubles o poco menos»/. Otros casos: págs. 37, 50.

25) La primera cita, con su primera línea sin sangrar, no admite objeción alguna (salvo la ya mencionada, en términos generales, de la incorrecta y antiestética excesiva altura de los corchetes, defecto de fábrica, como se dijo, que uno debe neutralizar: la cita no ha comenzado por un original con mayúscula de comienzo de frase. Sin embargo, en la segunda cita, con un inicio real de frase (por lo tanto, con mayúscula), esa primera línea debe ir sangrada. El hecho de que el bloque de la cita vaya sangrado no nos exime de sangrar, a su vez, la primera línea. Es un error muy extendido. Aplíquese a situaciones idénticas dentro del volumen (por ejemplo, pág. 56).

27) a=Mejor que /el armazón/ resulta /la armazón/: véase Manuel SECo, Nuevo diccionario de dudas y dificultades de la lengua española (Espasa Libros, Barcelona, 2011). $\mathbf{b}=$ Prácticamente, casi se impone la coma hiperbática, a pesar de la presencia del verbo tras el sintagma inicial, en /En su complicada andadura vital[,] logró disponer Coromines de una bibliografía adecuada para los fines del diccionario etimológico/.

28) Errata en /Mitteileungen/: sobra, como es evidente, la segunda $e$.

29) No habría resultado inoportuno, en la nota 14 , que apareciesen mencionadas estas dos fichas: $\mathbf{a}=$ mi artículo «Las etimologías hispánicas de Meyer-Lübke $(R E W)$ como fondo. Del maestro Américo Castro al discípulo Dámaso Alonso (1911-1923)», en Analecta Malacitana, XXIV-2/2001, págs. 519-524; b= en ese mismo volumen, Dámaso Alonso (por mí dispuesto para la imprenta), «Adiciones hispánicas al diccionario etimológico de W. Meyer-Lübke», págs. 527-554.

30) Aplicable en algún otro lugar, no puede iniciar página la forma /etc./: al quedar desligada de su antecedente sintagmático, debe reconvertirse en /etcétera/.

31) a= Además de con los nombres propios, no conviene cortar unidades léxicas «marcadas» tipográficamente - es decir: que lleven cursiva, versalita (sea redonda, cursiva o negrita), etc.- , razón por la cual inténtese al menos no cortar en casos como /Autori-dades/, a sabiendas de que en situaciones como la presente (o, en la misma página, /Tesoro lexico-gráfico/), de segmentos incisos largos, puede resultar muy complicado o incluso imposible. Más fácil, en cambio, resulta lograr que, en la nota $22, / 2$ pase a la línea siguiente para unirse a /tomos/. b=Ya se dijo algo en observación anterior: evítese, en la medida de lo posible, que una línea comience por /rr/o por /11, ñ/ no iniciales de palabra: en esta página, la última de esas letras. $\mathbf{c}=$ Por otro lado, aplicable a todo el volumen —no volveré a señalarlo- , hacen ruido las versales de DCEC y CSIC, que deben convertirse en versalitas o, cuando menos, seudoversalitas: DCEC, CSIC. $\mathbf{d}=$ En la nota 24 conviene dar la fecha de edición (1960, letras A-E) y otros datos necesarios del volumen que recogía los varios fascículos del Tesoro lexicográfico de Gili Gaya, no limitarse al lapso temporal, 1947-1952, de la aparición del conjunto de esos determinados fascículos. 
32-33) Tránsito de final de página y comienzo de la siguiente: aquí han confluido tres hechos (lo de nombre propio, inicio con /rr/ y cambio espacial): doble motivo para evitar/Sebastián de Cova-rrubias/. Casos parecidos, en págs. 33-34.

33) En la nota 33, mejor/microfilme/ que /microfilm/. Por otra parte, como no se trata de frase especificativa, sino explicativa (aunque cabría una interpretación muy próxima a la aposición), mejor colocar una coma en /(aunque en algunos casos acudió a la 1. edición[,] de 1607, que tenía en microfilm/.

34) a=Página muy ilustrativa... Casos varios de cortes en finales de línea de distinta naturaleza: cursivas, nombres de personas o lugares (/Fer-nando, OR-TIZ, Beney-te, Bil-bao, Saba-dell, Institu-to/) no difícilmente resolubles, integrables; además, algún sintagma numérico necesitado, por la ruptura de sus dos miembros, de repetición del guión al inicio de la siguiente línea (igual, por ejemplo, en pág. 35, nota 55). $\mathbf{b}=$ Por si faltara algo, errata acentuaria en /Andujar/.

36) Una vez aparece /van/ y otras /Van/ en /Willem... Eys/: unifórmese según la convención aconsejable.

38) a $=$ Preferible valerse de la coma hiperbática en /Para realizar estas tareas auxiliares[,] Coromines encontró alguna ayuda, pero no pudo librarse de tener que dedicarse personalmente a ellas en muchísimos casos/. $\mathbf{b}=$ Como algo más abajo aparece un segundo superlativo, /en lo que se separa es en la existencia de ligerísimas diferencias interpretativas/, tal vez convenga, por razones estilísticas, buscar alguna variante (superlativo no morfológico), pues en un texto científico siempre es preferible, no hallándonos en un entorno áureo de reproducción textual, rehuir cualquier situación que nos recuerde la lengua familiar, cotidiana. En la 12, /disfrutaban de una rarísima condición, había tenido después algunas tempranísimas experiencias/; en la 61, /indiscutidas a lo largo de un grandísimo periodo de tiempo/.

39) $\mathbf{a}=$ Hay dos frases, que no transcribo, en las que parece mejor solución prescindir de la coma delante de una /o/ que no es propiamente disyuntiva, sino más bien distributiva: conviene, pues, asociarla, a efectos de puntuación, a la conjunción $/ \mathrm{y} / \mathbf{b}=$ Por lo demás, resulta preferible la presencia de la coma hiperbática en /Si nos da cuenta de sus provisiones[,] es porque está dispuesto a cumplirlas a rajatabla, aun cuando se suela[n] colocar los pies de plomo de que podrían no alcanzarse si le flaqueara la salud u ocurriera alguna catástrofe general/.

40) $\mathbf{a}=$ Aunque sin tanta seguridad - pues lo anticipado no es extenso y el verbo viene a continuación y absorbe rítmico-anafóricamente a tal sintagma-, me inclinaría también, levemente, por recomendar la coma hiperbática en /Para esta agrupación[,] introducía las cédulas de cada uno de los grupos en pequeñas carpetillas de papel, poco mayores que las papeletas, o en varias, [suprímase esta coma] cuando el material no cabía en una sola/. $\mathbf{b}=/$ Iba apareciendo así en ciernes la organización por lemas/: por muy extendido que se halle ese plural, conviene atenerse a la forma genuina, prístina, /en cierne/, 'en flor', tan bien estudiada por Julio Casares a principios del siglo XX. 
41) Ya se han dicho unas cuantas cosas sobre los numerosos cortes objetables a final de línea. Uno verdaderamente tosco, de nula cultura tipográfica, es el que observamos aquí: /( $\$$ y, línea siguiente, los números respectivos, al final de los cuales se cierra, naturalmente, el paréntesis. Otros casos, en págs. 49 y 52.

43) Otro detalle nada ejemplar: dos líneas sucesivas terminan en /co-, Co-/, respectivamente; para acabar de rematar tan brillante estética, la tercera línea empieza «coherentemente» por /romines/: todo un prodigio de perfección... antitécnica, antiestética.

45) También aquí $-\mathrm{y}$ ahora, al no hallarse el verbo inmediatamente, en forma obligada - , habrá que plegarse a la consabida coma hiperbática: /A lo largo de su correspondencia[,] Coromines iba dando cuenta a Menéndez Pidal de sus descubrimientos sobre voces cuya explicación no era la esperable $[\ldots] /$.

47) Podría entenderse la coma cuya ausencia vamos a recomendar por cuanto en dicho segmento textual se dan dos «niveles conjuntivos» y parece inicialmente defendible no mezclarlos; pero la cuestión rítmica es muy importante y el sintagma /, cuando no dispongamos de datos,/ neutraliza anafóricamente ese aparente «exceso de velocidad» al permitir la mera sucesión lineal de dos estructuras copulativas de distinto nivel: /Lo haremos basándonos en las informaciones concretas sobre fechas que aparecen en las cartas dirigidas a Menéndez Pidal y a otros corresponsales, [mejor sin coma] y las supliremos, cuando no dispongamos de datos, con una ponderación del tiempo empleado para algunas letras, [coma aceptable, pero quizá resulte preferible no valerse de ella] en función del número de páginas/. Otra solución es mantener esa coma insertando una anterior tras /Pidal/, creando un inciso del todo aceptable.

48) Otra página no austera en «disgrafismos»: a=no se trata de corte, sino que se halla en la misma línea la forma /próxi-mos/: guión parasitario disruptor: errata, pues; $\mathbf{b}=$ dentro de un inciso de rayas, entre el final de una línea y el comienzo de la siguiente, /en los Oríge-nes-/; $\mathbf{c}=$ entre dos líneas, /al descanso/: conviene evitar un corte que lleve a la línea siguiente un elemento de palabra homófono de palabra (otros casos: págs. 52, 55, 57, 65); $\mathbf{d}=$ ahora ya última línea de esta página y comienzo de la siguiente: /sobre el tiempo que le que-daba/.

50) Como en materia de puntuación hay que tener siempre presente la estructura particular de una frase dada (la regla general solo sirve como ambientación previa al análisis particular), en /A mediados de febrero[,] Coromines indica a Carles Riba que está iniciando la letra $\mathrm{F}[\ldots]$, me he inclinado, como se ve, por servirme de la coma hiperbática. Insisto: toda puntuación responsablemente asumida es necesariamente estilística (nunca mecánicamente practicada): de ahí su enorme complejidad y la eficacia y belleza de una solución felizmente conseguida (que implica exactitud semántica y «armonía» prosódica/prosodia «armoniosa»).

51) Además de la minucia del inconveniente corte /Menén-dez Pidal/, presente, igualmente, en págs. 53, 59 y 61, no hay razón alguna para la coma antes 
de la prótasis o condicionante en /[...] y le aseguraba, sin temor a equivocarse, que terminaría la obra en un año, si las cosas no se torcían $[\ldots .$.$] / .$

53) Tenemos la siguiente información: «Pero la inconstancia de la fortuna lo trastocó todo: fallecido por entonces su maestro Jud, Francke solicitó un informe - posiblemente a Wartburg-, [informe] que, a pesar de ser muy favorable, sugería que el diccionario se podía abreviar considerablemente». En el legado de Dámaso Alonso (en la RAE) existe material epistolar en relación con este punto (las cartas de Corominas al creador y director de la Biblioteca Románica Hispánica de la Editorial Gredos), material que yo mismo, hace unos años (posteriormente a la fecha de edición del volumen objeto de análisis), en presencia de don José Antonio Pascual (a quien había invitado a dicho acto), me encargué de entregar a la muy responsable directora de la biblioteca de dicha institución, doña Rosa Arbolí, al mismo tiempo que sugería se le facilitasen al primer responsable, académico de número, del volumen epistolar dichas cartas «etimológico-editoriales», pensando, como suelo decir, en una necesaria edición ya «estabilizada» de la obra consabida. Dicho material proyectará luz sobre el hecho consignado en las citadas palabras. Complementariamente, remito al documento que, en la entrega siguiente, reproduciré en el comentario a la carta número 66 .

53-54) «Fue la solución que permitió disponer en no mucho tiempo de la obra impresa, gracias a que la editorial española supo entender la importancia de este libro: tanta como para hacer una gran inversión en maquinaria y en personal, que [/lo que, lo cual/ o /inversión que/] permitió componer un texto impecable $[. .]$.$) .$

54) «Emociona comprobar cómo Menéndez Pidal, que había seguido de cerca cómo se iba levantando ese extraordinario edificio, se muestra realmente sorprendido por lo conseguido [...]»: quedan demasiado cerca dos /cómo/: varíese.

54-55) Sin que parezca objetable en absoluto, probablemente resulte preferible la puntuación que sugiero (con la pareja de comas interpolada): «Su protagonista era simplemente una persona, no un superhombre; una persona que[,] mientras hacía su trabajo[,] no dejaba de pensar día a día en el retorno a la patria».

55) $\mathbf{a}=$ Evítense los cortes /Bue-nos Aires, exube-rante/; por supuesto, tampoco resultaría aconsejable /exuberan-te/ por razón ya comentada. $\mathbf{b}=$ Otra menudencia queda señalada en una observación anterior.

56) $\mathbf{a}=\mathrm{El}$ primer párrafo de la cita superior necesita del signo diacrítico $/[\ldots$.$] / ,$ tal como se ha hecho correctamente en otras ocasiones. $\mathbf{b}=$ Naturalmente, como se trata de cita, pero se ha adoptado el criterio de adaptar el texto a las normas actuales de acentuación, mayúscula/minúscula y puntuación (véase atrás I-5 y, más adelante, comentario a pág. 64), no habría visto como inoportuno que, por ejemplo, se interpolase una coma o, simplemente, se colocase (yo prefiero lo primero) en /Por lo demás, aunque esto se arreglara[,] tiene importancia muy secundaria frente al Diccionario/.

57) $\mathbf{a}=$ Mejor solución con esta coma hiperbática: «En sus ensoñaciones de regresar[,] iba aflorando cada vez con más fuerza la idea de que tan gran esfuerzo 
como estaba realizando terminaría por abrirle las puertas de la Universidad española o al menos de las del trabajo que se planeaba en el entorno de Pidal para realizar el Diccionario histórico»; cabría igualmente, con ventaja, situar entre comas el sintagma /al menos/: la frase ya es de por sí larga; $\mathbf{b}=$ de otra parte, tal como se explicó en $\mathbf{4 7}$, es preferible suprimir la coma tras /lejana tierra/ en «Coromines, a medida que se encontraba más seguro en su trabajo, experimentaba con más fuerza la añoranza de su lejana tierra, y se reafirmaba en su decisión de no querer demorar más el regreso a ella, dispuesto a aceptar cualquier trabajo que se le ofreciera allí»; c) no son buenas particiones /tam-bién/ $\mathrm{y} /$ dis-puesto/, aunque mejor ni siquiera dividirlas.

59) $\mathbf{a}=$ No es corte adecuado /《fi-lológicas»/: palabra marcada (por las comillas) y un comienzo, /lolo/, no ejemplar tipográficamente; tampoco /Me-néndez Pidal/. $\mathbf{b}=$ De acuerdo con el criterio por los editores adoptado de intervenir, algo cabría haber hecho (nota 82; lo hago yo ahora) en la cita «Y gran cosa es el trabajo de formación que usted consigue en los alumnos de ahí[,] pues por los temas de tesis en curso veo que serán del mayor interés»: podría incluso añadirse un juego de comas para /por los temas de tesis en curso/, pero, dado que entonces quedaría un /pues/ que nos obligaría a seguir leyendo para saber si era causal o ilativo, podemos conformarnos con la sola coma tras /ahí/ aunque no haya hipérbato (una explicación que aleje toda duda al respecto, en ambas situaciones, me obligaría a extenderme); no obstante, dado lo complejo del universo puntuario, tampoco resultaría objetable omitir la coma sugerida antes de /pues/, o sea, dejarlo tal cual.

59-60) Mal resuelta la transición entre las dos formas finales de la última línea, /bien po-/ y el comienzo de la página siguiente, /drían/.

60) $\mathbf{a}=$ Mal corte /Coro-mines/, lo mismo que /sino que ni si-quiera/. $\mathbf{b}=$ No es puntuación correcta - consecuencia de operar exclusivamente sobre la base de la cercanía más bien «designativa» (antes que semántica), en este caso, entre /pero/y /no obstante, sin embargo/_- la de «[...]para las efusiones del corazón; no obstante[,] hay algunas en que el discípulo reconoce paladinamente el profundo afecto que experimentaba por Menéndez Pidal, quizá exageradas, pero no insinceras», donde, como se ve, he interpolado la imprescindible coma.

61) Se entienden perfectamente sin comentario las dos interpolaciones comísticas necesarias (comas correlativas) que realizo en /Lo cual, contemplado desde la perspectiva que nos da la Historia[,] dista mucho de ser dramático; permite comprobar, en cambio, la importancia que hubiera tenido[,] en la que se conoce como Escuela de Filología Española, que las opiniones de su fundador no hubieran permanecido casi indiscutidas a lo largo de un grandísimo periodo de tiempo/.

62) En /[...] algunas de las cuales hubieran debido desprenderse con el paso del tiempo de algunos apasionados excesos interpretativos/, sin que se dé incorrección alguna y sin que parezca se haya buscado un determinado paralelismo estilístico, quedan muy cerca dos formas del indefinido /alguno/: cabe variación en dicho espacio sintagmático. 
64) En relación con la postura de los responsables de la edición acerca de los criterios de una discreta intervención en esos textos epistolares, formulada en esta página, envío al lector a I-5, donde algo digo al respecto.

65) a=Mejor que el término /paréntesis cuadrado/, simplemente /corchete/; $\mathbf{b}=$ por otra parte, quizá convenga estudiar la posibilidad de que lo denominado en esta página /paréntesis agudos: (>medio año $<$ )/ se llame /antilambdas inversos/; $\mathbf{c}=\sin$ que resulte objetable la original, prefiero esta otra puntuación: «No queremos terminar esta breve nota introductoria sin dar las gracias a quienes nos han ayudado en nuestra tarea,[;] de un modo particular[,] a [...]» (se menciona a seis personas).

67-68) $\mathbf{a}=$ Si en cubierta, con criterio tipográfico, no ortográfico, figura /Histoire Epistemologie [doble ¿errata? acentuaria o, simplemente, descuido por Épistémologie] Langage/, al traducirlo a ficha bibliográfica hay que transcodificar y colocar algún tipo de puntuación: basta fijarse en la portada, en la página de derechos y en otros espacios (o atender a la forma como ha sido fichado en diversos lugares) para actuar oportunamente; pero incluso si por doquier, que no es el caso, apareciese «apuntuariamente/acomísticamente», habría que pasar forzosamente del código meramente tipográfico (apenas virtualmente ortográfico) al explícitamente/formalmente ortográfico-puntuario (sin duda, comas). $\mathbf{b}=$ =Página, como algunas más, rica en desaconsejables cortes: /en M./ y, línea siguiente, /Pérez González/, /Latín Medie-val, en Europa y Amé-rica, Va-lladolid, Institu-to de Lingüística/, /pp./ y, página siguiente, /505-514/, /Bu-lletin Hispanique/,/pp./ y, línea siguiente, /209-218/, /Para-ninfo/. c= Finalmente: valdría la pena recoger en un volumen o dos los artículos aquí bibliográficamente presentes en torno a Coromines/Corominas de los responsables de la edición; añádanse el fichado atrás, II-4, más cualesquiera otros no mencionados, de ellos mismos, sobre dicho autor. Con bien conformados y minuciosos índices auxiliares, dicha obra sugerida prestaría un buen servicio.

SEGUNDA PARTE

\section{EL ENTORNO A TRAVÉS DE DIVERSOS TEXTOS COMPLEMENTARIOS}

0

En la observación a la página 53 se habló de determinado material epistolar (Corominas/Dámaso Alonso) que podía ayudar a esclarecer uno de los puntos necesitados de información para su cabal interpretación. Pues bien: en la presente sección voy a presentar, en orden cronológico, una serie de unidades epistolares inéditas que contribuirán a mejor entender las circunstancias históricas que arropan el núcleo textual, virtualmente historiográfico, del volumen centro de nuestra atención. Téngase en cuenta, para el origen de los materiales que pondré ante los ojos del lector (a partir de fotocopias), lo que digo en I-5. Modernizo la acentuación, suprimo la presencia ocasional de guiones detrás tanto del punto seguido como del punto y aparte en la primera de las cartas. En materia de puntuación, no la reajusto o corrijo mecánicamente, sino que interpolo siempre que lo juzgo necesario o casi. El tránsito de un texto privado a uno 
público obliga a revestirlo de todo lo necesario para su propio decoro en la nueva situación comunicativa (tal como habrían hecho los propios autores de esos textos) $\mathrm{y}$, además, porque tal proceder ayuda en la propagación de los «buenos modales/ hábitos puntuarios». Será el criterio que emplee cuando me ocupe (siguiente entrega) de los propios textos epistolares de nuestros dos corresponsales (véase atrás I-5). Los puntos suspensivos encorchetados al final de cada texto sustituyen a la firma y rúbrica del remitente.

\title{
V. Varia epistolar introductoria (con referencias onomásticas múltiples)
}

\author{
$\overline{\text { El Presidente de la Academia Nacional de la Historia }}$ \\ [Ricardo Levene]/Ramón Menéndez Pidal \\ (Buenos Aires, 10 de julio de 1939)
}

Ilustre y querido amigo:

Mucho celebro haber recibido noticias suyas después de tanto tiempo. Siempre lo recuerdo con afecto y admiración.

He leído su carta y[,] respecto de ella, le diré que, efectivamente[,] se está por designar un Profesor de Latín en la Universidad Nacional de Cuyo, de creación reciente. Tomo buena nota de su pedido y de las calidades del señor Corominas. Trataré de hacer lo posible a pesar de los diversos candidatos que aspiran a esa cátedra.

Por correo separado le hago enviar algunas publicaciones.

Lo saluda cordialmente su admirador y amigo invariable [.....

$$
\begin{gathered}
\frac{2}{\text { De María [Goyri, 1875-1954, esposa de RMP }]^{1}} \\
\text { Chamartín (Olivar de, Cuesta del Zarzal, domicilio en Madrid), } \\
\text { viernes, } 24 \text { de agosto de } 1945
\end{gathered}
$$

Deliciosa extensa carta, de trascendente interés humano, que comienza con «Queridos veraneantes... o invernantes». No es este el lugar para transcribirla completa; me limito a citar las dos primeras líneas del tercer párrafo (conforme avance esta sección, se comprenderá por qué lo hago así): «De correo, poca cosa. Un folleto del Sr. [Claudio Sánchez] Albornoz [1893-1984] y un estudio de su labor y unas tiradas aparte de [Clemente] Hernando Balmori [1894-1966]».

${ }^{1}$ Dirigida, prácticamente seguro, al matrimonio Miguel Catalán Sañudo (1894-1957)/Jimena Menéndez-Pidal Goyri (1901-1990), padres de Diego Catalán Menéndez-Pidal (1928-2008); estarían en su descanso veraniego en San Rafael (Segovia). 


\section{$\frac{3}{\text { Clemente Hernando Balmori/Ramón Menéndez Pidal }}$ \\ (Tucumán, 1o de julio de 1947)²}

Querido Don Ramón: recibí su grata acusándome recibo de Las Fenicias ${ }^{3}$ y estimulándome por ellas que mucho le agradezco.

Nuestra Universidad está ahora en plan de reformas fundamentales y[,] entre otras cosas[,] quiere crear un Instituto de Filología bien dotado. Para dirigirlo y organizarlo[,] se ha pensado en discípulos de V. y[,] por iniciativa del Prof. de Literatura, Prof. [Alfredo A.] Roggiano [1919-1991], se ha fijado la atención en Rafael Lapesa.

La propuesta que se le hace es la siguiente: Dirección del Instituto y eventualmente del Boletín que se empezaría a editar el año que viene. Sueldo mensual[,] $\$ 1.200$ pesos (posiblemente $1.800 \mathrm{si}$ el aumento de sueldos proyectado entra en vigor el año que viene), que es aquí una cantidad para vivir cómodamente. Viajes pagados para él y su familia y vuelta al cabo de dos años si así lo deseare. Además[,] estaría a cargo de la Cátedra de Filología de esta Universidad. La labor que podría realizar sería sumamente importante y[,] aun diría yo[,] necesaria. Es además una ocasión para tener aquí otro profesor español [en esa época Hernando Balmori no poseía todavía la nacionalidad argentina] que dirija los estudios de Filología en la escuela de V.[,] lo que sería de gran trascendencia. El momento es como pocos con autoridades favorables a la cultura hispánica que habría que aprovechar. Yo le rogaría[,] pues[,] que hable con Lapesa en este sentido, [coma sobrante] y[,] en caso favorable y si se considera oportuno[,] nosotros iniciaríamos por la embajada y consulado las demás gestiones que haya que realizar. Le remito una carta para él para que V. se la haga llegar y le ruegue nos conteste lo antes posible por vía aérea. Yo no sé su dirección concreta.

Además[] otra propuesta para Pabón [José Manuel Pabón y Suárez de Urbina, 1892-1978]: un contrato por dos años en las mismas condiciones de sueldo y viajes. Él daría las clases de Latín IV y Griego III y formaría parte de la Directiva del Instituto de Lenguas y Literaturas Clásicas y del Boletín que iniciaríamos el año próximo. Si al cabo de dos años quisieran quedarse por más tiempo[,] sería muy factible.

Hágame el favor de hacerle llegar esta carta después de hablar con él. Cualquier sugestión de V. sería bienvenida.

Le saluda afectuosamente su discípulo que constantemente le recuerda [...].

${ }^{2}$ No es escaso el número de cartas de nuestro corresponsal en la Fundación Ramón Menéndez Pidal: desde 1932 hasta 1954; se encuentra dicho material epistolar bajo dos entradas: la correcta, /Hernando Balmori, Clemente/, y la «anglicada», /Balmori, Hernando Clemente/. No quiero extenderme en la explicación de esta segunda modalidad, pero tiene relación con la formación estudiantil, en Estados Unidos, de la persona que en un determinado momento tuvo a su cargo la ordenación del material epistolar (compárese más adelante VI-3). Véase enseguida 3a.

${ }^{3}$ Eurípides, Las Fenicias, texto de Gilbert Murray; traducción, introducción y notas de Clemente Hernando Balmori, Universidad Nacional de Tucumán (Facultad de Filosofía y Letras, Clásicos de la Literatura, 1), San Miguel de Tucumán, 1946. 
Como habría resultado engorroso y antiestético, además de imposible de compaginar, presentar el material del que inmediatamente daré noticia, he creado esta unidad duplicada, como volverá a ocurrir tras el siguiente número, con una serie de datos que añaden información sobre Clemente Hernando Balmori. Son estos (extraídos de un sobre grande que yo mismo rotulé hace años en la Fundación Ramón Menéndez Pidal).

1) En 1957 se abrió un concurso de méritos en la Universidad Nacional de La Plata para cubrir dos cátedras: Filología Hispánica (aspirantes: Clemente Hernando Balmori y Marcos Augusto Morínigo, 1904-1987) y Lingüística (aspirantes: Clemente Hernando Balmori, Demetrio Gazdaru, 1897-1991, Carlos Alberto Disandro, 1919-1994, y Carlos Alberto Ronchi, 1922-2010). Desde esa universidad enviaron, dentro del mismo sobre, los respectivos historiales, mecanografiados en folios prolongados, de dichos candidatos; el más extenso y más estéticamente preparado, el de Demetrio Gazdadru (40 páginas perfectamente encuadernadas); el de Ronchi, en dos bloques (2+4), 6; Morínigo, 4; Hernando Balmori, 2.

2) Reproduzco la carta (24 de febrero de 1957), firmada desde la Universidad Nacional de La Plata por /Prof. Oberdan Caletti/ (Rector Interventor), 1913-1976, y /Dr. Bernardo Canal Feijoo/ (Decano Interventor), 1897-1982, y con el encabezamiento /Al señor profesor||Don Ramón Menéndez Pidal,|MADRID/:

Tengo el agrado de dirigirme a Vd. para acusar recibo de su muy atenta nota del 19 de enero último, por la cual comunica su aceptación, junto con la de sus eminentes colegas Dámaso Alonso y Salvador Fernández Ramírez, para la integración del Jurado que ha de entender en el concurso abierto por esta Facultad de Humanidades para proveer de profesor titular las cátedras de Lingüística y Filología Hispánica.

En nombre del señor Rector de la Universidad Nacional de La Plata y en el mío propio, debo expresarle el más profundo reconocimiento por la colaboración que presta en la formación de nuestro claustro de profesores, colaboración que honra altamente a esta Facultad.

Por este mismo correo aéreo, en paquete separado, se procede al envío de los antecedentes de los inscriptos, separados en tres juegos para cada uno de los señores miembros del Jurado.

Al reiterarle mi gratitud, aprovecho esta ocasión para saludar a Vd. con mi más alta consideración, rogándole quiera hacerse intérprete de mi respetuoso saludo ante los señores Dámaso Alonso y Salvador Fernández Ramírez [debajo, firmas y rúbricas]4.

${ }_{4}^{4}$ Dentro de esta unidad documental hay también una breve carta de Salvador Fernández Ramírez (Madrid, 8 de marzo de 1958): «Querido Don Ramón: le envío, según sus deseos, uno de los expedientes de los candidatos para las cátedras de La Plata y envío hoy otro ejemplar a Dámaso Alonso.ILe saluda con el mayor afecto [...]». Ambas cátedras fueron ganadas por el profesor Hernando Balmori (según observamos en el artículo fichado al final de esta sección, 13, en a, pág. 90). 
4

Rafael Lapesa/Ramón Menéndez Pidal
(desde Lourido, Vigo, 4 de agosto de 1947)

Mi querido don Ramón:

Recibo hoy su carta del 25. No tengo aquí los materiales para la edición del Rimado, así que de momento no puedo aclarar nada de lo que consulta Corominas ${ }^{5}$. Pienso estar en Madrid a principios de septiembre y entonces veré lo que hay. Desde luego[,] me gustará ponerme en comunicación con un hombre que está haciendo tan excelente labor. Lo conocí hace muchos años, cuando él acababa de venir de Suiza y yo, todavía estudiante, ayudaba a Julia Keller en su tesis [Universidad de Zúrich, 1932] sobre el Alexandre [Contribución al vocabulario del Poema de Alixandre, Tipografía de Archivos, Madrid, 1932]; pero desde aquellos tiempos no hemos tenido relación.

También cuando vuelva a Madrid y haya regresado Casares [Julio Casares, 1877-1964], que está ahora en Asturias, le pediré el tomito que Vd. indica. Corominas podrá disponer pronto del Corpus Glossariorum, pues[,] según me dijo Gili[,] la primera entrega (la A entera saldrá en este otoño), y muy pronto la B [véase atrás IV, cuarta observación de pág. 31].

En los últimos días de estar en Madrid tuve una gran alegría al pasar varios ratos con Amado Alonso [1896-1952; desde 1927 en Buenos Aires; ahora, en uno de sus viajes a España]. ¡Qué hombre extraordinario en todos los aspectos y qué lástima que no quede entre nosotros!

Que acabe de pasar bien sus vacaciones. Saludos de Pilar [Lago Couceiro, su esposa, 1900-1984] y de los dos a doña María e hijos. Le abraza [...].

$$
4 a
$$

En relación con la presencia de Julia Keller en la carta anterior, vale la pena reproducir el texto «Corominas», firmado por Rafael Lapesa, en el diario $A b c$, lunes, 12 de junio de 1989, pág. 26 (sección «Cartas al Director»; sin intervención editorial del remitente):

Señor Director. En ABC del martes, 6 de junio[,] página 73 [cuarta columna], se da cuenta de la conversación que sostuve el lunes con don Antonio Astorga [titulada «Lapesa: "Es el gran arquitecto del léxico español y catalán"»] cuando me enteró de que el Premio de las Letras había sido otorgado al profesor Juan Corominas y yo manifesté mi gran alegría por tan justo galardón. La versión publicada contiene algunas inexactitudes que me interesa aclarar, aunque sean explicables tratándose

${ }^{5}$ Véase ahora Canciller Pero LóPez de Ayala, Rimado de Palacio: «Esbozo de edición crítica por Rafael Lapesa Melgar. Con la colaboración de Pilar Lago»; Prólogo de Trini Miró Mira, Consellera de Cultura y Deporte; Introducción de Giuseppe Di Stefano: Generalitat Valenciana, Conselleria de Cultura i Esport, Biblioteca Valenciana, València, 2010. 
de un diálogo sostenido por teléfono. Mi encuentro con Corominas en caso [casa, en Madrid] de Julia Keller no fue en 1920, cuando él tendría 15 años y yo tenía 12 [Lapesa: 1908-2001; Corominas: 1905-1997], sino en $1928^{6}$. No fue Corominas[,] sino yo, quien ayudaba a la doctoranda suiza en su tesis, [;] y no lo hacía «de manera ejemplar», sino como aprendiz novato. La tesis no versaba sobre el vocabulario «de los poemas de Vicente Aleixandre», que en aquel año 28 publicaba su primer libro, sino sobre el léxico del Libro de Alexandre, el poema del siglo XIII. Por último y sobre todo: yo no dije que Corominas hubiera rehusado ser académico «porque entendía [él, Corominas] que no lo merecía» [-] ¿quién con más méritos?-[,] sino porque[,] al igual que otras grandes figuras de nuestras letras, no le atraía tal honor, cualesquiera que fuesen las razones.

$\frac{5}{\text { Clemente Hernando Balmori/Ramón Menéndez Pidal }}$
Tucumán, 12 de agosto de 1947

\section{Querido Don Ramón:}

Se ha cumplido lo que me temía. Acabo de recibir carta de Pabón en la que me dice que su estado de salud no le permite aceptar nuestra invitación. Por lo tanto[,] le confirmo lo dicho en mi anterior[,] o sea[,] el de encontrarnos el profesor de Griego y Latín que necesitamos como extraordinario para dos años, prorrogables, en las mismas condiciones que le expresé en mi última.

Espero muy pronto su grata nueva.

Salúdale afectuosamente su discípulo [...].

${ }^{6}$ Frente a la errata /en caso/, he optado, no sin vacilación, por catalizar /en casa/, y no /en el caso/, que habría resultado, por otra parte, mecánicamente más enrevesado, menos natural; normalmente, habríamos dicho /en el domicilio/: no resulta presumible que una doctoranda extranjera tuviese casa en Madrid, aunque ciertamente podía haber vivido en una casa de familia (española o no). Sin duda, si en lugar de $/$ caso=casa/ se hubiera empleado la voz /domicilio/ - fuera casa, piso o apartamento-, no habría surgido tal ocasión y el verme obligado a una nota tan aparentemente anodina como esta, en la que, otrosí, tampoco estoy seguro de haber dado en la tecla «trans-errática». En un primer intento, me había inclinado por interpolar simplemente /el/ porque en 1932 ya Lapesa pertenecía al Centro de Estudios Históricos (rama filológica; 1927-1928, becario; 1929-1939, colaborador) y, como ocurría en situaciones como esta, el lugar de encuentro era la propia sede o lugar de trabajo de maestros y aprendices bajo la guía última de Ramón Menéndez Pidal. No obstante, al cambiar de hipótesis, me incliné por pensar que la doctoranda tendría el grueso de sus materiales en su domicilio y que sería allí, no cargando con ellos al CEH, donde Lapesa le ayudaría (¿?). En todo caso, solo examinando, en los archivos del periódico (¿?) o en Valencia (legado Lapesa), si nuestro autor escribió con papel carbón para copia (¿?) el original —más que probablemente, manuscrito — de esa nota lapesiana, cabría advertir si la errata se encontraba en el propio consabido texto (más bien no: prácticamente seguro por la propia materialidad de su carácter manuscrito) o surgió al componerse en dicha publicación periódica. En fin, nos hallamos frente a una verdadera «aporía metaerrática» para cuya resolución nos veríamos obligados a contar con algunos datos, biográficos o no, sobre todo relacionados con Julia Keller, que nos apartarían inconvenientemente de los prudentes límites del presente trabajo. 


\section{$\overline{\text { Rafael Lapesa/Ramón Menéndez Pidal }}$ Lourido, 18 de agosto de 1947}

Mi querido don Ramón:

Desde que recibí su carta estoy pensando en posibles candidatos para ir a Tucumán. No es, desde luego, buen momento, porque los que ya están asentados en España se embarcarían acaso para Norteamérica, pero no para Argentina; y por otra parte, los jóvenes no situados aún tienen a la vista la perspectiva de cinco o seis cátedras universitarias que van a anunciarse a oposición. De gentes hechas y garantizables[,] se me ocurren los nombres de Salvador Fernández Ramírez [1896-1983], Alonso Zamora [1916-2006] y Ramón Aramón [Ramon Aramón i Serra, 1907-2000]. Pero Salvador me parece orientado hacia Norteamérica y Zamora acaba de poner casa en Salamanca, muy contento de tener al fin lugar de asiento. Aramón, tan obstinadamente ceñido a lo catalán, difícilmente repetiría el caso de Corominas. Blecua [José Manuel Blecua Teijeiro, 1913-2003] sería también un gran elemento, pero aunque habla con frecuencia de ir algún día a Estados Unidos, dudo mucho que quiera salir de su Zaragoza para ir a Tucumán. ¿Y Sanchís Guarner [Manuel Sanchis Guarner, 1911-1981]? Haría muy buen papel, por inteligente y bien preparado; pero tanto él como Rodríguez Castellano [Lorenzo Rodríguez-Castellano, 1905-1986] tienen de momento el compromiso del Atlas [ALPI]. De hornadas posteriores[,] son pocos los que podrían, con madurez suficiente, dirigir un Instituto de Filología. ¿Acaso [Manuel] Muñoz Cortés [1915-2000], bien conocido por Vd., o Emilio Lorenzo [1918-2002] $]^{7}$, discípulo predilecto de Dámaso?

Escribiré a Salvador, Zamora y Blecua, los tres únicos de quienes tengo dirección aquí, diciéndoles que se dirijan a Vd. o me contesten a mí. Es lo único que se me ocurre.

Con afectuosos saludos de Pilar, sabe le quiere [...].

$$
7
$$

José Vallejo (Sánchez, catedrático de latín, 1896-1959)/ Ramón Menéndez Pidal San Sebastián, 25 de agosto de $1947^{8}$

Mi querido D. Ramón: Reexpedida de Madrid y de Santander[,] recibo su carta relativa al profesor de Lenguas Clásicas que piden para Argentina. La cosa no parece fácil, pero creo que se podría encontrar a alguien capacitado para el puesto. Habría que hacer algunas consultas, pero estos días de dispersión de la gente impiden que se pueda ir de prisa en el asunto.

7 Suprascrito, y con letra probable de Menéndez Pidal, se lee «va a Filadelfia», donde en efecto estuvo (University of Pennsylvania, 1947-1948).

${ }^{8}$ Probablemente se hallaba pasando unos días de vacaciones. La carta es de enorme interés (toca asuntos relacionados con información sobre la lengua vasca, etc.), pero me voy a limitar a transcribir los dos primeros párrafos, los aquí pertinentes. 
Yo vuelvo dentro de muy pocos días a Madrid y desde allí le volveré a escribir, salvo que V. me indique algo en contrario.

\author{
8 \\ Salvador Fernández Ramírez/Ramón Menéndez Pidal \\ Madrid, 27 de agosto de 1947
}

Querido don Ramón: me ha escrito Rafael Lapesa, diciéndome que le indicó a usted mi nombre, juntamente con los de Zamora y Blecua, como posibles candidatos para atender a la petición de Hernando Balmori para la Universidad de Tucumán. La idea no me pareció mal y no sé si me hubiera animado. Pero si alguna vez me lanzo a una aventura así - lo cual nunca ha estado enteramente fuera de mis cálculos-[, tendría que esperar a que mi hija mayor termine su licenciatura el próximo curso. De todas maneras[,] no he querido dejar de darle a usted cuenta de mi decisión, para que, en vista de las otras respuestas, pueda usted contestar a Hernando Balmori. Aprovecho la ocasión para enviarle a usted mis saludos y para desearle un buen verano[,] que, según me dicen, ha sido ahí [en San Rafael, donde veraneaba el maestro] hasta ahora de una temperatura muy agradable. Muy afectuosamente su discípulo [...].

9

Rafael Lapesa/Ramón Menéndez Pidal (en su casa de campo de San Rafael, Segovia) Madrid, 10 de septiembre de 1947 (el penúltimo corchete, léxico, es de Lapesa)

Mi querido don Ramón:

En estos días últimos de mi veraneo en Galicia he ido recibiendo cartas de Alonso Zamora, Salvador Fernández y Blecua. Ninguno de los tres se anima a ir a Tucumán. Últimamente me ha escrito Fernando Lázaro, muy interesado. Supongo recordará Vd. quién es, porque creo ha ido alguna vez a saludarle en Chamartín y enseñarle algo de sus trabajos. Es muchacho joven - 23 o 24 años-[,] pero muy trabajador, inteligente y bien orientado. Ha hecho una tesis, al parecer muy buena, sobre las teorías gramaticales en el siglo XVIII español9. La lástima

9 Las ideas lingüisticas en España durante el siglo XVIII, anejo XLVIII de la Revista de Filología Española, Consejo Superior de Investigaciones Científicas, Madrid, 1949; nueva edición, Editorial Crítica (Grupo editorial Grijalbo), Barcelona, 1985. Esta contiene un extenso e importante prólogo de Manuel Breva Claramonte, págs. 7-19, con una muy oportuna y amplia bibliografía por él elaborada, págs. 19-34; igualmente, una hermosa, e historiográficamente significativa, Advertencia del autor, págs. 35-36. Cito las primeras líneas tanto del segundo párrafo como del tercero: «Lo elaboré a los veinticuatro años, y no lo había releído entero desde entonces. Lo he hecho ahora, y he tenido que considerarlo con bastante indulgencia en muchos de sus lugares: mi inexperiencia y mi ignorancia se transparentan en trechos demasiado frecuentes.\| Entre tantas aprensiones, no he dejado de estimar, no obstante, algunas cualidades del libro. Aporté en él múltiples datos poco o nada conocidos, y los sometí a una sistematización que aún considero válida. Hube de alumbrar las ideas lingüísticas en multitud de libros y de manuscritos considerados de escaso interés, y que eran exponentes de un siglo 
sería que se fuera sin completar en Europa su formación. Él cuenta con que en Tucumán estaba Terracini, pero ya le advierto que no sé si sigue ${ }^{10}$. Yo le he dicho que le escriba a Vd. con su resolución definitiva.

Hoy veré qué se puede contestar a Corominas sobre [a]sendreado-asendereado. Iré a la Nacional para comprobar la lectura del ms. $\mathrm{N}$ de Ayala [véase atrás carta número 4].

Que pase muy bien este final de vacaciones. Con saludos de Pilar, reciba los muy afectuosos de su siempre discípulo [...].

\author{
10 \\ $\overline{\text { Alonso Zamora Vicente/Ramón Menéndez Pidal }}$ \\ Salamanca, ácrona (tal vez finales de 1946 o comienzos de 1947)
}

Mi querido Don Ramón:

Manual García Blanco ha sido mensajero del encarguito de Tucumán. Ya hacía unos días que Lapesa me había hablado algo del asunto. Yo no sé qué hacer. Son, como V. comprende, muchas las cosas que, a la vez, empujan y retienen. ¿V. cree que debo ir? ¿Me querrá V. explicar lo que haya de eso y lo que V. piensa? Deme su consejo leal.

Yo me iría. ¿Podría conseguirse del Ministerio que me guardaran mi cátedra aquí? Ha habido casos, me dicen, que hasta les han pagado aquí. Yo tendría que dejarme a mi madre, que no quiere moverse: edad, achaques, raíces. Una vez allí: ¿es bastante lo que ofrecen para vivir? Somos gente de necesidades mínimas. ¿Cómo está aquello de medios de trabajo? Quizá V. lo conozca. ¿No estaba allí Terracini? ¿Qué fue de él? [véase atrás nota 10].

Claro que yo sé muy bien que todo habría que dejarlo ante la necesidad de mantener aquello en marcha, si es que existe, y de que la escuela [naturalmente, de Ramón Menéndez Pidal] persista. Lucho entre mis cosas familiares, mi creencia en lo mío, que me dice que dónde voy yo, si lo que necesito es europeizarme más [compárese atrás carta número 9], es decir: estudiar un poquillo y mi afán de escapar un poco de tantas cosas corrientes en nuestra vida universitaria actual. En fin, dirá V. que todo esto qué le importa. Dígame lo que haya de concreto: condiciones, fechas, etc.

Hace cosa de quince o veinte días le mandé a su dirección de Madrid una cosita que he hecho sobre Valle Inclán. ¿Le llegó?

Sabe con cuánto cariño le recordamos [María Josefa Canellada (1913-1995) y yo] [...] $]^{11}$.

de intensa vida española, manifestada en torno a problemas centrados en el ámbito intelectual y hasta político. Me atrajo de ese siglo la poca atención que se le prestaba, estando en él, como está, el arranque de nuestra modernidad».

${ }^{10}$ Benvenuto A. Terracini, 1886-1968. Enseñó en la Universidad Nacional de Tucumán entre 1941-1946; gran amigo de Amado Alonso. Véase su necrología, firmada por Salvador BuccA, en Filología, XIII/1968-1969 (Homenaje a Ramón Menéndez Pidal), págs. 441-443.

${ }^{11}$ Intensa presencia afectiva (diminutivos, cercanía comunicativa, «realia») la del genio creador literario - escritura polifónica, sinfónico-orquestal - y agudo investigador de nuestra lengua 


$\frac{11}{\text { Corominas/Academia Sueca }^{12}}$

The Chairman

Svenska Akademiens Nobelkommitté

\title{
Dear Sir:
}

I have the honor to address, through your intermediation, the Swedish Academy, in order to nomínate Mr. Ramón Menéndez Pidal, as a candidate to the 1956 Nobel Prize of Literature.

I confidently expect the Committee fully to appreciate Mr. Menéndez Pidal's admirable accomplishments, both on a world and on a Hispanic scale, which make him what he is in the opinion of my fellow scholars and myself: the person in the world most deserving of that high distinction.

Yours sincerely

\author{
John Corominas \\ Author of Diccionario Crítico Etimológico de la Lengua Castellana \\ Professor of Romance Philology and Head of the Section of Spanish \\ Language and Literature, The University of Chicago \\ Member of the Institut d'Estudis Catalans
}

con su literatura Alonso Zamora Vicente. En relación con el trabajo aludido, cabe pensar
que se trata de «El modernismo en la Sonata de Primavera», en Boletín de la Real Academia
Española XXVI-120/1946, págs. 27-62; recogido en su libro De Garcilaso a Valle-Inclán,
Editorial Sudamericana, Buenos Aires, 1950, págs. 183, portadilla, y 185-243. Es imprescindible
consultar el más que incitante volumen de Mario PedRAzuela Fuentes (prólogo de Manuel Seco)
Alonso Zamora Vicente: vida y filología, Publicaciones de la Universidad de Alicante, 2010;
véase, dentro del capítulo tercero, el epígrafe 3.7, «El Instituto de Filología de la Universidad
de Buenos Aires», págs. 233-265; particularmente en relación con el asunto de esta carta,
págs. 233-234; aquí se verá por qué razón, de tipo médico, no aceptó el ofrecimiento de Tucumán.
12 Esta carta se halla en la Fundación Ramón Menéndez Pidal dentro de una abundante
documentación relacionada con el Premio Nobel de 1956. La hoja se halla grapada con un
texto, de página y media, escrito en español y dirigido a la Academia Sueca y al Comité para
la adjudicación del Premio Nobel del año mencionado. El documento procede del Rector,
Decanos y Profesores de las diversas Facultades de la Universidad de Sevilla. Como el hecho
de aparecer grapados ambos textos no significa necesariamente, dados sus distintos orígenes,
su pertenencia al mismo entorno, he preferido limitarme a reproducir exclusivamente el
escrito de Corominas; y lo hago respetando incluso la disposición mecanográfica del original.
En la copia de dicho texto aparece al final, manuscrito y desde su dirección particular en
España/ (Carretera de Sarriá, 37, Barcelona), lo siguiente: «En la primera sesión propondré al
Instituto que haga lo [palabra apenas iniciada en la fotocopia: /mismo/]. Saludos muy atentos J. C.». 
12

$\overline{\text { Clemente Hernando Balmori/Dámaso Alonso }}$

(La Plata, 16 de abril de 1957) ${ }^{13}$

Distinguido y recordado amigo Alonso: Cuatro líneas para saludarle y anunciarle la llegada a esa [Madrid] del Director de la Biblioteca de esta Universidad de La Plata que va por esa creo que con una beca para realizar estudios de su especialidad. Es un conocido escritor que hace poco ha recibido un premio nacional y que, sobre todo, tiene el mérito de una alta categoría espiritual ${ }^{14}$.

Él le lleva una tarjeta mía de presentación para V. y mis saludos. Yo le agradecería le atienda y ayude a orientarse para el mayor provecho de su misión.

Él le informará también de las cosas de acá. En un terreno plenamente objetivo[,] le voy a rogar envíen, en cuanto les sea buenamente posible, el dictamen sobre las cátedras de Filología y de Lingüística que esta Universidad ha encomendado a V. conjuntamente con don Ramón y Fernández Ramírez.

Por tratarse de materias muy especializadas[,] se creyó oportuno buscar fuera del país un alto tribunal de la más alta competencia.

Por otra parte[,] los intentos anteriores para un tribunal de acá había encontrado dificultades e impugnaciones.

Yo me había presentado a estas solas dos cátedras; una cátedra aquí tiene una magra retribución de 1.800 pesos sueldo básico y la solución que se ha encontrado es la de que cada profesor desempeñe dos o tres cátedras.

He ganado en concurso tres cátedras en Tucumán. Pero necesitaba venir cerca de Bs. As. Por el hecho de que las bibliotecas del interior son tan pobres[,] que no se puede trabajar. Y como el año 49[,] después de ganar aquí en La Plata el concurso de Filología, fui despojado de ella por intrigas, se me devolvió la cátedra ganada en aquella ocasión, pero esta ha salido a concurso como todas en todo el país. En Tucumán he desempeñado la de Lingüística por más de 10 años y estoy realizando estudios de lenguas indígenas que creo están dando buenos resultados. Por esto opté por presentarme a esta, ya que[,] con solo la de Filología, no podría presentarme y trasladarme a La Plata.

He encontrado siempre dificultad de movimientos en mi vida académica aquí. Las dificultades provienen de sectores que no podría uno imaginarse. Afortunadamente,,] el alumnado y las autoridades me han defendido ardientemente, pero el prestigio ganado lo ha sido a pulso. Creo que esta explicación podrá ayudarle a comprender las circunstancias.

${ }^{13}$ Solo aparece el escueto /Alonso/ del saludo epistolar; por el entorno hispanoamericano, cabría haber pensado en Amado Alonso (pero, como es sabido, había fallecido en 1952) o en Alonso Zamora Vicente (véase nota anterior). Sin embargo, ateniéndonos a lo que se dice ya hacia el final de la carta, es evidente que se trata de Dámaso Alonso (1898-1990), conocidos ambos, cuando menos, por sus relaciones en el primer tercio del siglo pasado: Centro de Estudios Históricos, revista Emerita, etc.

${ }^{14}$ Se trata, salvo error por mi parte, de Juan Manuel Villarreal, que fue director de esa biblioteca entre noviembre de 1955 y septiembre de 1967. 
Recibí hace tiempo su trabajo en el tomo IV del Homenaje a D. Ramón con los antecedentes griegos y latinos de la poesía correlativa moderna ${ }^{15}$. ¿Piensan aún dedicar un VII tomo? ¿Por qué no se ha invitado a más gente de por acá? Concretamente, me gustaría haber sido invitado ${ }^{16}$.

Saludos a Salvador Fernández. ¿Podría saber la dirección de Lapesa? Me escribió hará ya un año y no le he escrito porque se me extravió la carta en los azares de mis idas y venidas entre Tucumán y La Plata.

Mis respetuosos saludos a su señora [Eulalia Galvarriato, 1904-1997] y V. reciba un abrazo de su afmo [...].

13

$\overline{\text { LOS CONSABIDOS DOS GRANDES ESTUDIOSOS DE NUESTRO ESPACIO TEXTUAL }}$

a) Dirijámonos al esclarecedor artículo de Ana María BARRENECHEA y Élida LoIS «El exilio y la investigación lingüística en la Argentina», en Cuadernos Hispanoamericanos, 473-474/1989, págs. 81-91. En dicho trabajo se habla fundamentalmente de cuatro sobresalientes filólogos: Amado Alonso, Américo Castro, Joan Corominas (págs. 88-89) y Clemente Hernando Balmori (89-91). Son datos de mucho interés los que aparecen en esta necesaria contribución historiográfica $\mathrm{y}$, de citar en relación con los dos investigadores que ahora ocupan nuestro centro de interés, habría que hacerlo realmente en su integridad textual, razón por la cual, valorada la importancia de ese texto, simplemente pongo de relieve su oportunidad, solicito atención sobre lo llamativo de su desconocimiento u omisión por parte de quienes podrían haberse servido de él y, sin más, invito a los lectores, particularmente a los que se ocupan de asuntos historiográficos, a que lo tengan muy presente $\mathrm{y}$, además, disfruten de su contenido.

b) Como investigación de gran valor para el entorno filológico argentino (y que, así pues, afecta a Corominas), me place añadir la muy reciente y más que enjundiosa obra (verdaderamente, llena, con suma responsabilidad, un hueco historiográfico) de Miranda Lida Años dorados de la cultura argentina. Los hermanos María Rosa y Raimundo Lida y el Instituto de Filología antes del peronismo, Eudeba (Editorial Universitaria de Buenos Aires), 2014. Añado, pues no resulta tan alejado de dicho entorno, Alfonso REYEs, Grecia (prólogo y selección de Teresa Jiménez Calvente), Fondo de Cultura Económica y Cátedra Alfonso Reyes del Instituto Tecnológico de Monterrey (colección Capilla Alfonsina; Antologías temáticas con textos deAlfonso Reyes, VIII), México, D.F., 2012. He sabido de esta edición a través de la reseña de Álvaro Bustos en Revista Cálamo-FASPE, 63/2014, págs. 104-106; aquí se menciona el volumen

\footnotetext{
15 «Antecedentes griegos y latinos de la poesía correlativa moderna», en Estudios dedicados a Menéndez Pidal, Consejo Superior de Investigaciones Científicas, Madrid, IV, 1953, págs. 3-25; recogido en el volumen, en colaboración con Carlos Bousoño, Seis calas en la expresión literaria española, Gredos, Madrid, 1951, ${ }^{4} 1970$, págs. 281-308.

16 Dicho homenaje constó de siete tomos (el último, con dos volúmenes: el segundo, índices): 1950-1962; no se dio colaboración de nuestro corresponsal.
} 
de correpondencia de Alfonso Reyes con Raimundo Lida y María Rosa Lida publicado en Buenos Aires en 2001.

\title{
TERCERA PARTE \\ $\overline{D O S ~ A N T I C I P O S ~ N E C E S A R I O S}$
}

\section{Una incomprensible ausencia (preanunciada): Clemente Hernando Balmori ${ }^{17}$}

\author{
0
}

En un trabajo de un distinguido lingüista, ya no entre nosotros, en texto suyo años ha publicado se narraba el hecho de que, leyendo una determinada obra como parte de la preparación de un estudio, al llegar a una particular aseveración que chocaba frontalmente contra sus cimentados conocimientos, no pudo por menos que abandonar la lectura (desconozco si en algún momento logró reanudarla: no dice nada al respecto). Pues bien: en el volumen del que me ocupo, yo también tropecé con un... grave error que conmovió, vamos a decir, mi fibra intelectual. No obstante, pasado ese breve lapso temporal de tenso desagrado lector, proseguí con mi tarea hasta dar cima - como siempre, bolígrafo en mano- a esos textos epistolares con todo su entorno. De otro modo: el espíritu constructivo que procuro darle al conjunto de mis indagaciones científicas me ayudó a superar ese mal trago, a proseguir con la tarea que, contra viento y marea, me había propuesto. El desarrollo subsiguiente irá mostrando el sentido de lo expresado en estas líneas introductorias.

\section{$\frac{\mathrm{A}}{1}$}

En efecto: nos hallamos en el texto de la carta número 9 (París, 26 de junio de 1939), de Menéndez Pidal a Corominas. En ella se habla de Amado Alonso, de Ricardo Levene y de Ricardo Rojas, vale decir, de un entorno plenamente argentino. A manera de complemento de dicho texto epistolar, podemos leer (pág. 94): «La advertencia de A. Alonso sobre la inseguridad del éxito [a saber: que Corominas sea contratado como profesor de Latín en la Universidad de Cuyo, Mendoza] no le desanime a usted lo más mínimo. Es precaución natural. Lo mismo hizo en el caso de Hernando, que fue nombrado ya». De aquí arranca la sorprendente, a pesar del terreno poblado de señales historiográficamente cristalinas, nota 5 , que reza así:

Tal vez aluda a Teófilo Hernando (1881-1976), médico español. Discípulo de Ramón y Cajal, había ampliado sus estudios en Estrasburgo y Berlín gracias a una «pensión» de la Junta [para Ampliación de Estudios e Investigaciones Científicas]. Catedrático de Farmacología en la Universidad de Madrid desde 1912, fue miembro de la Real Academia de Medicina

${ }_{17}$ Nace en Llanes, Oviedo, 1894; fallece en Buenos Aires, 1966. /Hernando/ no es segunda unidad de un nombre compuesto, sino primer apellido. Material introductorio, como insinúo, el presentado en la SEGUNDA PARTE, cartas números 3, 3a, 5, 8, 12, así como los dos párrafos del último segmento, 13. 
y de la Junta de [para] Ampliación de Estudios e Investigaciones Científicas. Se exilió en Francia al comenzar la Guerra Civil y, aunque volvió a España en 1941, no recuperó su cátedra hasta el mismo día de su jubilación, en 1951.

2

Veamos ahora, en cambio, cómo reacciona Nuria Gregori Torada (Presentación y notas de) en José Ma Chacón y Calvo (1892-1969), Diario íntimo de la revolución española (escrito en 1936 entre el 22 de julio y el 15 de noviembre), Instituto de Literatura y Lingüística, La Habana, 2006 (existe nueva edición, de Jorge Ferrer, en Verbum, Madrid, 2009). Nos hallamos con una carta de Menéndez Pidal que, a petición mía, amablemente me facilitó en su día Julio Rodríguez Puértolas, colega cuando ambos nos hallábamos en activo en la Universidad Autónoma de Madrid. Leemos (pág. 224; en la edición madrileña, págs. 175-176): «De Hernando mucho deseo que Ud. Pueda llevarlo ahí[,] como me augura». La nota 383 (en esa misma página; nota 122, pág. 175, en la edición española: las separo aquí mediante pleca doble negrita):

Es muy posible que se refiera a Clemente Hernando Balmori(Asturias 1894-Buenos Aires 1966). Director [no así: véase más adelante párrafo 6, ficha 6, texto de Rodríguez Adrados] de la Sección de Lingüística y Filología Clásica del Centro de Estudios Históricos de Madrid y de la Revista Emérita [Emerita], donde publicó notables trabajos. Durante la GCE [Guerra Civil Española] se exilió en la Argentina. Fue profesor de latín y griego de la Universidad de Tucumán. Fue miembro del Instituto Nebrija ${ }^{18}$.| Clemente Hernando Balmori (Asturias, 1894-Buenos Aires, 1966), filólogo y profesor exiliado en Argentina.

3

Antes de proseguir con algunas menudencias bibliográficas, conviene ya plantar una importante obra, muy anterior al año 2006, que, a falta de la documentación esperable por parte de los responsables de la edición del volumen epistolar, habría resuelto con creces tal perturbadora ausencia informativa. Se trata del libro Clemente Hernando Balmori. Textos de un lingüista, de Diana Balmori (hija de nuestro autor), Ediciós do Castro/Do Grupo Sargadelos (serie Documentos), Sada-A Coruña, 1998, 552 págs. En las dos últimas líneas de cuarta de cubierta, se lee: «Diana Balmori [residente en Estados Unidos] contou en Galiza coa colaboración de Charo Portela, na que delegou instruccións para o coidado da obra». El prefacio - muy bien acompañado de no pocas fotografías, algunas de interés etnográfico-, págs. 7-87; dentro de él, como «Post Scriptum», aparece un hermoso texto (págs. 79-84) de Miguel V. Olivera sobre el Instituto de Filología de la Universidad de La Plata y la figura, tan generosa en virtudes

${ }^{18}$ El Instituto Antonio de Nebrija de Filología Clásica ya pertenece al período 1939-1985; antes, en el Centro de Estudios Históricos, su nombre era Sección de Estudios Clásicos (véase más adelante párrafo 6, ficha 6, Rodríguez Adrados). 
humanas y tan creadora científicamente, del Dr. Hernando Balmori. La bibliografía, págs. 85-87, se divide en las siguientes secciones: 1) El lenguaje; 2) Lenguas indígenas; 3) Lenguas diferenciadas; 4) Otros. Luego viene un Apéndice (págs. 89, portadilla, y 91-552) con multitud de textos, más de nuevo algunas fotografías de nuestro autor reproducidas facsimilarmente e incluso, manuscrito, un Diccionario vilela, letras $a, b, c$ (págs. 139, portadilla, y 140-252); dentro de este Apéndice se halla, igualmente, la muy clarificadora nota necrológica, págs. 274-275, redactada por Salvador Bucca, texto que debe considerarse complementario del antes mencionado del profesor Olivera.

4

No puedo ahora detenerme a examinar esta instructiva obra (que, mucho antes del año 2006, ya podía consultarse tanto en la biblioteca de la Real Academia Española como en otras de universidades gallegas: Santiago de Compostela y La Coruña) con algunas sugerencias de posible utilidad, por si algún día se reedita, y me limito a señalar, fuera de dicho propósito, cómo una figura, Clemente Hernando Balmori, ligada inicialmente a las lenguas clásicas desemboca en el estudio, muy intenso, de las lenguas indígenas. Pensemos, de una generación posterior, en la decisiva, por no decir trascendental, atención que el insigne Antonio Tovar (1911-1985) prestó a esa zona de estudio. Menos conocido, y de distinto alcance, es el caso de otro gran hombre de las humanidades: Julio Calonge (1914-2012). En el volumen recopilatorio Estudios de lingüística, filología e historia (dispuesto para la imprenta por quien esto escribe; prólogo de Alberto Bernabé; Gredos, Madrid, 2005), en el capítulo XXX, «En torno al autor del libro», podemos leer (pág. 487):

En el curso 1945-46, y hasta el de 1951-52, además de ser Profesor Encargado de Curso de Lengua Griega en la Universidad de Sevilla, es nombrado Profesor Encargado de Curso de Introducción al estudio de las lenguas indígenas de América. Durante cerca de siete años se dedicó al estudio y la docencia de estas materias, incidiendo especialmente en los problemas de distribución de lenguas y en su estructura gramatical. Inició el estudio de la lengua quechua.

5

Antes de continuar en esta sección, cabe preguntarse cómo puede explicarse el «deslizamientoonomástico»o, mejor, «trastruequeonomástico-historiográfico»,el colocar a /Teófilo Hernando/ en lugar de /Clemente Hernando Balmori/. Como no se trata de un fenómeno, aplicado a otros casos, que solo haya podido darse una vez, la presente, conviene llamar la atención sobre lo imprescindible de operar siempre con una visión universal de los hechos; instalados dentro del hispanismo, no podemos laborar sin manejar, como realidad esencial, el ámbito hispanoamericano y, ya dentro de España, mirando por doquier; de otro modo; debemos estar alertas ante cualquier situación investigadora que 
pudiera asociarnos al «provincianismo (anti)científico». Sé que ello implica una disciplina férrea en nuestras tareas de estudio, pero, por razones éticas, no podemos escapar de tal coerción. Con este espíritu comprehensivo, nunca podré entender que un hispanista pueda llevar adelante sus investigaciones alejado de libros y revistas del mundo clásico (Emerita, por ejemplo). Ello habría permitido - aplicando tal realidad a nuestro ejemplo — que cualquier hispanista reconociera inmediatamente a nuestro personaje (con presencia viva en la publicación periódica acabada de mencionar entre 1933 y 1936). Idea en la que siempre he insistido aquí y allá y que sinteticé «paradigmáticamente» en «Algunas ideas básicas en torno a la disciplina Lengua Española», págs. 963-970 en el vol. II de La lingüística como reto epistemológico y como acción social. Estudios dedicados al Profesor Ángel López García con ocasión de su sexagésimo aniversario (editores: Montserrat Veyrat Rigat y Enrique Serra Alegre), Arco-Libros, Madrid, 2009; aquí podemos leer (pág. 967):

\begin{abstract}
Y, por supuesto, entren sin más dilación, con la imprescindible y justa «carga de profundidad», viejas asignaturas esenciales y «caleidoscópicas» bajo el rótulo de Latín y Griego. Llenemos nuestra despensa con «dosis masivas», casi terapéuticas, de esas dos lenguas primigenias sustentadoras de los fundamentos de nuestra cultura; integrémoslas con naturalidad en nuestra vida intelectual: somos filólogos... ¡Cuánta desolación y orfandad, cuánta falta de conciencia histórica sin la presencia generosa de esas fuentes nutricias!
\end{abstract}

\title{
$\frac{\mathrm{A}}{6}$
}

Ya no tanto para volver sobre la ausencia comentada, sino sobre todo para presentar nuevos datos en torno a Clemente Hernando Balmori, me voy a permitir hacer desfilar una serie de fichas, anteriores y posteriores al año 2006, de las que tengo a mano en mi archivo científico, vale decir, sin llevar a cabo investigación alguna al respecto. Sigo un orden cronológico.

1. Sin firma, en Residencia. Revista de la Residencia de Estudiantes, I-2/1926, «XV Curso de Vacaciones», págs. 180-187, aparece en la 183 una fotografía, «Grupo de profesores del Curso». Se dan los nombres de todos ellos; de pie, el primero a la derecha, /D. Clemente Hernando/. También se reproduce esta fotografía en la página 144 (en trabajo de Neus Vila Rubio) del volumen fichado más adelante, $\mathbf{6}$.

2. Tovar, Antonio, «Sobre la escuela de Menéndez Pidal», en La Torre, XVIII-XIX/70-71/1970-1971 (Homenaje a Ramón Menéndez Pidal), págs. 75-93. Podemos leer (págs. 81-82):

Las lenguas prerromanas de la Península me habían interesado, pues no en vano en aquel año, decisivo para mí, que pasé yendo todas las tardes cuatro horas al Centro de Estudios Históricos, Clemente Hernando 
Balmori, uno de los colaboradores de nuestra sección, que luego moriría en el exilio [como ya sabemos, en Buenos Aires], había hecho una expedición a Portugal y había traído un calco de la inscripción lusitana de Lamas de Moledo. En la pared de una de las dos salas de que disponíamos, el enigma de las letras reproducidas en el relieve del papel había desafiado mi curiosidad.

3. Polo, José, «El español familiar y zonas afines (ensayo bibliográfico», en la revista Yelmo desde el número 1/1971 al 28/1976. Pues bien: en la primera entrega, sección III, «Miscelánea preliminar», epígrafe 4, «Hablas especiales», fiché su trabajo «Habla mujeril» (en Filología, VIII/1962, págs. 123-138), recogido en el volumen citado atrás, 3, págs. 512, portadilla, y 513-528. Manejé, igualmente, su excelente reseña (1950) a una determinada obra de Manuel Criado de Val sobre los tiempos (1948) al preparar mi colaboración a un homenaje a este último investigador (publicado en 1989), pero, como en dicho trabajo finalmente no me hice cargo de las recensiones, he preferido en este momento no extenderme en los datos bibliográficos $\mathrm{y}$, simplemente, dejar constancia del hecho como otro de mis acercamientos a un texto del estudioso hispano-argentino.

4. López SÁnchez, José María, Heterodoxos españoles. El Centro de Estudios Históricos, 1910-1936, Marcial Pons, Madrid, 2006. Leemos:

La sección de estudios clásicos venía a ser un intento de poner en práctica en Madrid lo que la JAE [Junta para Ampliación de Estudios e Investigaciones Científicas] no pudo desarrollar en [la Escuela Española de] Roma. Su director fue Giuliano Bonfante[,] que contó con Vicente García de Diego, José María [Manuel] Pabón y Cayetano [Clemente] Hernando Balmori como colaboradores y formaban el consejo de redacción de la revista [pág. 122; omito la nota 75].|l Los principales colaboradores [de Emerita] fueron Giuliano Bonfante, Vicente García de Diego, José María [Manuel] Pabón y Cayetano [Clemente] Hernando Balmori. Estos investigadores se decidieron por llevar a la práctica una lingüística histórica, pero no ya de base estrictamente comparativa al modo de los primeros indogermanistas ni tampoco adscrita a los estrechos parámetros de la ley fonética neogramática, sino más bien libre de estas ataduras y apoyándose en un método filológico que diera cabida también a la historia literaria y a la crítica de textos antiguos [353-354].\| En fin, en Emérita [Emerita] tuvieron cabida trabajos sobre sintaxis como los de Hernando Balmori o José María [Manuel] Pabón, estudios gramaticales a cargo de A. Magariños, investigaciones fonéticas como las de A. Cuny o lexicográficos de Giuliano Bonfante [354].

5. García Jurado, Francisco, «Los estudios de Filología Clásica», en Santiago López-Ríos Moreno y Juan Antonio González Cárceles (coordinación, diseño y edición de), en La Facultad de Filosofía y Letras de Madrid en la Segunda República. Arquitectura y Universidad durante los años 30, Sociedad Estatal 
de Conmemoraciones Culturales, Ayuntamiento de Madrid y Ediciones de Arquitectura. Fundación Arquitectura COAM, Madrid, 2008, págs. 296 (reproducción facsimilar) y 297-305. Dentro del epígrafe «Profesores ayudantes», leemos (págs. 303-304):

Los ayudantes venían a representar la savia nueva de la comunidad académica, más importante, si cabe, en una Universidad como la de Madrid, donde una gran parte de los profesores era de edad avanzada. Durante estos años encontramos cinco ayudantes: Bonifacio Chamorro, Ricardo Espinosa Maeso, Agustín Gómez Iglesias y las únicas mujeres de nuestro relato, Juliana Izquierdo Moya y Matilde López Serrano. Ricardo Espinosa, ayudante de prácticas de Lengua Griega durante dos cursos (1934-1935 y 1935-1936) a propuesta de Pedro Urbano [González de la Calle], enseñó, además, lenguas clásicas en el famoso Instituto-Escuela de la Junta para Ampliación de Estudios, junto a otros prometedores docentes, como Abelardo Moralejo y Clemente Hernando Balmori [omito nota 34].

6. Rodríguez Adrados, Francisco, «El Centro de Estudios Históricos, Emerita y los estudios clásicos, hoy», en José Manuel Sánchez Ron y José García-Velasco (edición de), 100 años de la JAE. La Junta para Ampliación de Estudios e Investigaciones Cientificas en su centenario. Actas del II Congreso Internacional 100 JAE (Madrid, 4-6 de febrero de 2008), Fundación Francisco Giner de los Ríos y Publicaciones de la Residencia de Estudiantes, Madrid, 2010, t. II, págs. 194, reproducción facsimilar de la portada del primer tomo de la revista (1933), y 195-211. Cito:

Pero volvamos a Emerita, a sus primeros volúmenes. La presentación de Emerita, cuyos cinco primeros volúmenes conservo como oro en paño, no puede ser más modesta. Figura como editor el Centro de Estudios Históricos, [;] la Sección de Estudios Clásicos no es mencionada (es posterior, ya dije). No se da nombre de director; en el volumen 1 aparecen como redactores G. Bonfante, V. García de Diego, C. Hernando Balmori y J. M. Pabón. Y falta el volumen 6, que debía corresponder al año 1938: el traslado del Centro a Valencia, por causa de la guerra civil, es el origen de esta discontinuidad [pág. 198].\|l Me gustaría citar, en el volumen 1, como autores de artículos, a C. Hernando Balmori, José Manuel Pabón y Giuliano Bonfante [...][198]..l Este grupo tenía varias raíces: había en él catedráticos de universidad como Pabón (de Latín), García de Diego y González de la Calle (de Latín y Sánscrito [,respectivamente]; de instituto como Magariños y Hernando Balmori; arqueólogos, como García Bellido; hombres de Iglesia, como el padre Jiménez, y un becario, Tovar [199].\|l Otros colaboradores que perdió Emerita fueron los ya mencionados Hernando Balmori, Sánchez Barrado y González de la Calle, que se exiliaron en América. Estas fueron pérdidas considerables. Allí, como otros varios estudiosos 
de varias disciplinas, hubieron de disminuir su labor en lenguas clásicas y emprender otros estudios (caso también de Bosch Gimpera). Pero de Sánchez Barrado no he encontrado huellas, [;] sí, en cambio, de los otros dos [208].\|l Hernando, que había publicado en España sobre Latín y lenguas prerromanas, sobre todo, vivió en Tucumán, luego desde 1949 en La Plata, enseñando en dichas universidades. Tuvo grandes problemas políticos por sus posiciones republicanas y antiperonistas. Tradujo del latín a Bacon y trabajó en lingüística española, pero sobre todo en el campo de las lenguas indígenas (quechua, otras lenguas sudamericanas, también sobre etnología americana y el teatro indígena). También en estudios etnológicos. Tengo datos hasta 1965 [208; muere Clemente Hernando Balmori, como sabemos, en 1966; véase atrás párrafo, no ficha, número 3, atención a obra esencial].

\section{La irrefragablemente laboriosa Maria Woitscheck (con su leve presencia)}

\section{1}

Ya en III-1-8 apareció este nombre cuando señalé una errata — que ahora, al citar inmediatamente, dejamos intacta (una primera $e$ que debe ser $o$ ) en su apellido. En la carta número 96 (de RMP a Corominas, 7 de febrero de 1964; «tarjetón con membrete») podemos leer: «[...] saluda a D. Juan Corominas y le envía otra serie de estudios que la Sra. María Weitscheck [1lamada de nota] le manda con el ruego de remitírselos a usted ${ }^{19}$. Yo no he tenido tiempo para ver otras hojas que me manda a mí. ¿Qué juzga usted de ella? ¿Las ha visto usted [las páginas anteriores]?». La anunciada nota de los editores reza así: «No hemos identificado a esta corresponsal (véase el comentario de Pidal en la carta 97)». Bien: he intentado conseguir algunos datos en torno a dicha estudiosa y alguna cosa he obtenido, a pesar de la enorme dificultad (no he encontrado en las bibliotecas madrileñas, ni siquiera en la Biblioteca Nacional o en la Biblioteca Hispánica, diversas obras de Heinrich Cunow sobre los incas traducidas del alemán al español por ella hacia el final del primer tercio del siglo XX y publicadas en Lima), con paciencia y con la ayuda de varias personas cuyos nombres irán apareciendo en el siguiente párrafo.

19 En expresión no marcada, habríamos esperado /y le envía otra serie de estudios que la Sra. María Woitscheck me manda con el ruego de remitírselos a usted/. No debe, sin embargo, considerarse incorrecta la configuración sintáctica de que se ha valido RMP, sino más bien - dentro del espacio de proyección de una especie de «dativo ético de la alteridad» o «asimilación sintáctica regresiva»- de fusión, en lo designado, entre el complemento indirecto le, que, catafóricamente, ya mira en forma irremisible, atraído por un imán, hacia el de destino (destinatario en el plano de la designación), igualmente le: este segundo ya estaba presente en la «conciencia finalista» del remitente; es como si se hiciera desaparecer la intermediación del mensajero para ir directamente al grano: material que debe parar en las manos de quien más importa, Corominas. No obstante todo lo acabado de expresar, a partir de la idea, que yo repito una y otra vez, de que los textos son siempre más potentes/poderosos que todos nosotros, no se descarte, sin salirme del mecanismo explicado, la posibilidad de que, dada la proximidad formal y funcional, se trate de mera errata: le por me... 
1) Entre otras búsquedas, me dirigí al Goethe-Institut de Madrid el 21 de febrero del año 2013 con la idea de conseguir información sobre dicha hispanista; naturalmente, en el texto por mí enviado ofrecía algunos datos (de los que aquí presento) para crear el entorno necesario como ayuda en dicha búsqueda. La señora Moka Seco (Bibliothek, Ausleihe) me contestó amablemente y, aunque modestamente señalaba «[...]pero hasta el momento nuestras pesquisas han sido bastante infructuosas», me ha hecho llegar un documento de mucho interés con datos varios que nos permiten saber que Maria Stephanie Woitscheck nació el 27 de septiembre de 1900 y que el 3 de marzo de 1922 había solicitado un puesto de trabajo escolar (Schulamtsbewerberin) en Breslau [Breslavia; actualmente, Polonia: Wrocław].

2) Haciéndose cargo de una sugerencia mía en el sentido de reenviar mi solicitud a algún centro universitario alemán (pensaba en Wiesbaden), con buen criterio la Sra. Seco lo ha hecho a la biblioteca Goerres en Madrid, desde donde Fr. Regine Baumeister me comunicó (8 de marzo) lo siguiente: «Estimado Sr. Polo:\|Lamento mucho tener que decirle que no he encontrado el nombre de Maria Woitscheck en ninguna de nuestras biografías ni en las diversas ediciones de Kürscners Deutscher Gelehrten-Kalender (el primero es de 1940). La única mención de su nombre la he visto en Internet, donde figura como traductora de alguna obra sobre Sudamérica [Perú...]. Parece que no llegó a estar en ninguna universidad como profesora. Por otro lado, si se hubiese casado, en aquellas épocas probablemente habría adoptado el apellido del marido, por lo cual se perdería la pista.ll Si me quiere dar algún dato más, lo miraría con mucho gusto.\|Un cordial saludo [...]».

3) Unos días después (el 12) recibo contestación de doña Rosa Ma Villalón Herrera (Archivo Documental del Centro de Humanidades, sección Fondo del Antiguo Centro de Estudios Históricos, Centro de Ciencias Humanas y Sociales del Consejo Superior de Investigaciones Científicas): «Estimado Sr. Polo: ॥ Siento decirle que no hemos podido localizar ninguna información sobre Maria Woitscheck entre los fondos que el archivo ha trabajado. Espero que podamos servirle de más ayuda en una próxima ocasión.\| Un cordial saludo $[\ldots] \gg$.

4) Aún dentro de marzo de 2013, he podido consultar, de Jesús de la Hera MartínEZ, la importante obra La política cultural de Alemania en España en el período de entre-guerras, Consejo Superior de Investigaciones Científicas, Madrid, 2002. En su página 61 podemos leer: «El personal con que contaba el Centro [de Intercambio Intelectual Germano-Español; Die Arbeitsstelle für deutsch-spanische wissenschaftsbeziehungen; Madrid] lo constituían, aparte de H. Obermaier y G. Moldehauer: Federico Ruiz Morcuende, director de los cursos de español, desde 1925; José Gavira, responsable del Boletín Bibliográfico, desde 1925; las señoritas Maria Woitschek, desde 1925, e Irene Brude, de 1926 a 1927, como secretarias [...]».

5) El día 15 contesta doña Pilar Uguina Cocostegüe (Instituto Cervantes, Madrid) a un correo mío del 12: "Estimado José:\|Ya nos hemos puesto en contacto con los bibliotecarios de nuestros centros en Cracovia y en Varsovia y nos han enviado un documento que tal vez le sea de utilidad.\|Ellos siguen la búsqueda de información y, en cuanto tengamos algo más, positivo o negativo, se lo enviaremos. ILe incluimos un listado de distintas bases de datos y repositorios, así como de los recursos electrónicos del Departamento de Bibliotecas y Documentación de Madrid, donde hemos realizado las búsquedas pertinentes para localizar datos sobre esta mujer y así descartar distintas fuentes de información.llTodas esas búsquedas nos han dado 
bibliografía que tal vez usted tenga ya recogida, así como un artículo que escribió María sobre Educación en Alemania, publicado por un diario español (en el documento adjunto está claro).\|Esperamos haberle sido de utilidad y seguiremos en contacto.\| Saludos cordiales y buen fin de semana [...]». Se halla algún documento que ya poseía por gestión anterior, al igual que otros datos de su actividad profesional: Lehrerin (Preußische Volksschullehrerkartei; Regierungsbezirk: Liegnitz [Lignitium; hoy día, Legnica, en la Baja Silesia, Polonia]). El artículo aludido, sugestivo y muy orientador, es «La enseñanza en Alemania», en La Esfera (Madrid), año XV, número 751, 26 de mayo de 1928, págs. 8-9 (a tres columnas y con sendas fotografías de cuatro universidades). Como en los demás casos, le agradecí el esfuerzo: «[...]Muchas gracias, Pilar, por la más que interesante documentación enviada. Poco a poco vamos estrechando el cerco en esta compleja y fecunda búsqueda. Un saludo cordial [...]».

6) Dentro aún de marzo, día 20, me remite doña Pilar Uguina las direcciones informáticas de dos puntos de referencia alemanes a los que podría dirigirme para continuar con la búsqueda consabida. Escribo inmediatamente a ambos. Enseguida (día 21) obtengo respuesta de Herr Pult (Hessisches Hauptstaatsarchiv, Wiesbaden). Se me comunica que Maria Woitschek figura en el anuario o directorio de 1966 como Fremdsprachenkraft ('del personal afecto a la enseñanza de idiomas') y anota su domicilio en esa época, así como el que aparece en la edición de 1981; menciona a un librero, Peter Woitschek, probablemente de su familia, y señala igualmente el domicilio registrado desde la edición de 1971 del anuario; que no se han encontrado más datos sobre ella entre la documentación de ese archivo y me sugiere otro archivo (indicado previamente por mi corresponsal del Cervantes, ya mencionada), al que ya me había dirigido.

7) Unos días después, el 26, recibo información, en polaco, de Wiesława Głąb (Documentalista Superior del Archiwum Uniwersytetu Wrocławskiego= Archivo de la Universidad de Wrocław); me dirijo a la Embajada de Polonia para rogarles la traducción y, muy eficazmente, al día siguiente, 27, me escribe el Sr. Maciej Bernatowicz (Primer Secretario: Asuntos de Prensa y Asuntos Económicos, Departamento Político-Económico) con la versión del original epistolar. Tras el saludo, «Buenos días», se lee: «En respuesta a su solicitud, dirigida al Archivo por la Biblioteca Universitaria en Wrocław el día 22 de marzo de 2013, informamos que el apellido M. S. Woitschek/Woitscheck no figura en nuestro registro de los alumnos que habían defendido su tesis doctoral en la Facultad de Filosofía de la Universidad de Wrocław antes de 1945. El inventario de datos de los años 1811-1945 se puede ver en nuestra página web: www.archiw.uni.wroc.plll.Se puede informar también en los registros de los estudiantes de los años 1918-1925 gratuitamente en la sala de lectura del Archivo, que está abierta de lunes a viernes de 9 a 14 (salvo agosto y los miércoles) o encargar a un empleado del Archivo (1 hora de búsqueda cuesta $20 €$ independientemente del resultado).\|Atentamente [...]».

8) Me encuentro ya a cierta distancia temporal (19 de mayo, igualmente de 2013) $\mathrm{y}$, no habiendo recibido contestación a tres correos electrónicos lanzados al aire para la consecución de nuevos datos (entre ellos, el del año de fallecimiento de esta más que laboriosa investigadora, Maria Woitscheck), doy por conclusa mi modesta indagación. Frutos más granados cabría obtener en el círculo de estudiosos que puedan moverse documentalmente con fluidez entre los dos núcleos atrás, párrafos 1 y 2 , mencionados. 
En la carta de 17 de febrero de 1964 antes referida aparece la siguiente frase: «Le da también las gracias por su información sobre la señora alemana chiflada [omito la nota 3]». Bien: esta última expresión - más bien fática, mimética, tal vez, de la transmitida por nuestro etimólogo - delata con claridad el juicio que los materiales etimológicos aludidos le habían merecido a Corominas. En mis colaboraciones científicas me he visto, en más de una ocasión, obligado a desfacer más de (en)tuerto o aseveración tópica errada en torno a más de una figura de la lingüística en general o del hispanismo lingüístico; por supuesto, no voy a detenerme a presentar los datos bibliográficos pertinentes (resultaría prolijo). Como simple lector, y más en cuanto filólogo, observo rasgos de incoherencia y de falta de cortesía para con Maria Woitscheck: una vez que se ha adoptado el criterio de no «censurar» el texto de esa correspondencia, señalando mediante puntos suspensivos encorchetados la supresión de determinados segmentos textuales, no puede quedar mecánicamente a la vista del lector la consabida expresión, en el fondo, disfemística, sino que, incluso por razones éticas, hay que desplegar todo el esfuerzo necesario (lo que yo he intentado: compárese 2, con sus diversos pasos) para lograr saber más acerca de dicha estudiosa y, con tal conocimiento, neutralizar, al menos en cuanto expresión, lo que en un texto que sale a la luz pública opera negativamente y, tras un análisis concienzudo de esos materiales etimológicos, puede incluso resultar desacertado, por no decir injusto, precipitado axiológicamente. El problema está -el lector lo habrá captado - en el desajuste entre lo expresado en un documento privado y su tratamiento cuando, por su publicación, ya ha dejado de ser privado. Por lo tanto, o en letra de molde se suprimen determinados segmentos textuales (y asunto «hermenéutico» resuelto) o, si tales expresiones salen a la luz pública (criterio que solo puede adoptarse en cada una de las situaciones, no en general), se impone un determinado aparato crítico que anule, total o parcialmente, los efectos negativos de un juicio sobre una persona que ya no puede defenderse. Puesto que, cual ha podido verse atrás con mis búsquedas en torno a Maria Woitscheck, no era fácil obtener información amplia, cuando menos habría debido escribirse una nota en la línea de que, naturalmente, la expresión de Corominas constituye un desahogo afectivo o primera reacción ante unos determinados materiales, pero que, naturalmente, sin examinarlos no podríamos tener, a pesar del exabrupto de Corominas, un juicio ecuánime, pues el universo etimológico es suficientemente complejo como para que no podamos alegremente, en primera instancia, lanzarnos a valoraciones exacerbadamente apodícticas.

4

Bien: mostrada ya la aparente «aporía intertextual» provocada por el mencionado «desajuste diafásico», enderezo la cuestión hacia la propia materia objeto de valoración. Digo que, al no ser etimólogo, no me hallo en condiciones de poder neutralizar el juicio de Corominas sobre los materiales enviados 
por la estudiosa alemana, aunque, de entrada, me duele tal visión, sobre todo, entre otras razones, porque, junto a las grandes virtudes del etimólogo español, también ha mostrado, vía escritura (al parecer, según leo en entrevista al primero de los responsables del presente volumen epistolar, no coincidente mecánicamente con juicios manifestados oralmente), en más de una ocasión, una determinada actitud nada alejada de lo dogmático y rígido frente a tesis contrarias a sus planteamientos científicos; desconozco si una recopilación textual detallada, y comentada, de tales situaciones «antimetodológicas-textuales» daría para todo un volumen.

5

$\overline{\text { UNA LANZA POR... LÁZARO }}$

Por ejemplo, entrando en una especie de excurso y ciñéndome a un solo caso, la reseña que publicó de la primera edición, 1953, del Diccionario de términos filológicos (Gredos, Madrid), de Fernando LÁzARo CARRETER, en Thesaurus. Boletín del Instituto Caro y Cuervo, XIII/1958, págs. 222-229. Se trata de un texto virtualmente inadecuado desde el punto de vista «estilístico» (prepotente y quién sabe si hasta agresivo): con modos científicos más bien toscos (¿cercanos al exabrupto?); y, junto a determinadas aseveraciones certeras, tampoco exento de algún error y de afirmaciones no plenamente fundadas ${ }^{20}$.

20 Percepción, igualmente digna de respeto, distinta de la mía es la de Francisco ABAD Neвот, «Fernando Lázaro Carreter (1923-2004). Bibliografía fundamental», en Boletín de la Sociedad Española de Historiografía Lingüistica, 4/2004, págs. 11-18, donde, entre las páginas 14-15, podemos leer: «La reseña de Corominas [...] resultaba agridulce: "así el autor como los editores merecen nuestro agradecimiento" - manifestó-, a la vez que señalaba hechos concretos que según el maestro catalán suponían errores y diversas limitaciones. Por supuesto[,] las discrepancias de Corominas se hallan expuestas en tono estrictamente profesional, sin las ansiedades personales que a veces son muy notorias en algunas reseñas».Ya desde la perspectiva bibliográfica, en La Corónica, 26-1/1997, hay toda una sección, «Critical Cluster: Homage to Joan Coromines», con doce colaboraciones precedidas de las palabras del Guest Editor, Francisco A. Marcos Marín (págs. 5-7). Pues bien: la primera de las contribuciones es, justamente, como cabía esperar, «Joan Coromines i Vigneaux, 1905-1997: A Bibliography», de Donna M. Rogers, págs. 9-24. El párrafo que sirve de introducción comienza con las siguientes palabras: «The following bibliography is as complete as was possible as of September 1, 1997. Publications are listed according to the type of material (books, articles, etc.) and are listed chronologically within each section». Me sorprende, sin embargo, que no aparezca - hallándose presentes sus textos recensionísticos- la reseña del diccionario acabado de fichar a pesar de que Thesaurus. Boletín del Instituto Caro y Cuervo era una revista de primera línea. En principio, cabría pensar que se trata de un fallo técnico en ese trabajo bibliográfico (ya sabemos que tales recopilaciones no son tan fáciles como a primera vista pudiera parecer); pero, al menos en teoría, si la bibliografía hubiera sido preparada desde alguna lista facilitada por dicho filólogo a alguno de sus discípulos o depositada en alguna de las instituciones cercanas a él, no habría que descartar que el propio autor hubiese preferido eliminar dicho texto, dado su carácter algo más que polémico, como si estuviera arrepentido de haberlo redactado en los términos en que apareció. Consignado lo anterior, me he permitido consultar Josep FERrer i COSTA, «Bibliografía de Joan Coromines», en Antoni M. Badia i Margarit/ Joan Solà, eds., con la colaboración de Ernest Rusinés, Joan Coromines, vida y obra, 
Esa actitud o tendencia poco ejemplar no la exhibió Corominas únicamente en esta ocasión: no sé si incluso podríamos aseverar que es "clásica», con determinadas reacciones dentro de «su universo etimológico» y en algún otro espacio de la investigación. Pero el caso de ahora posee una intrahistoria muy particular. Veamos: en la «Nota [de F. Lázaro] sobre la segunda edición» (1963; redactada en 1961), el segundo párrafo comienza así: «Los perfeccionamientos que puedan observarse en esta edición son debidos, en gran parte, a la cortés y benévola atención con que fue recibida la primera por la crítica. Efectivamente, he tenido en cuenta las siguientes recensiones bibliográficas $[. .]\rangle.\rangle^{21}$. Tras una extensa lista, acaba ese párrafo con las siguientes palabras: "Acepten todos la expresión más sincera de mi gratitud. Conozco también la reseña que J. Corominas ha publicado en Thesaurus, 1958, 222-229». En el «Legado Dámaso Alonso», Real Academia Española, se halla un denso texto mecanografiado de 13 páginas, en folio prolongado, «Réplica a J. Corominas» (título presente tanto en portadilla, donde se lee además /abril, 1961/, como en la primera página), que Fernando Lázaro le había enviado, en copia, a su maestro Dámaso Alonso, texto que nunca apareció publicado en Thesaurus (en carta a D. A., con fecha de 5 de mayo de 1961, le comunica que ya ha enviado el texto a Bogotá: «[...] veremos si se deciden a publicarlo»; no se olvide que Corominas asesoraba al Instituto Caro y Cuervo en determinadas cuestiones filológicas) ${ }^{22}$.

Editorial Gredos, Madrid, 2012, págs. 563-604. La sección F, reseñas, va cronológicamente de 1937 a 1968; las correspondientes a 1958, fichas 10-13, págs. 587-588. Pues bien: tampoco en esta última bibliografía aparece la reseña consabida, lo que, en teoría, nos obliga a situarnos de nuevo frente a las dos opciones de la alternativa líneas atrás mencionada, aunque ahora, tras la sintomática repetición de la ausencia de dicho texto recensionístico, casi se ve uno obligado a pensar que, en efecto, su autor Corominas no se habría sentido cómodo con dicha recensión, o incluso arrepentido de ella, y la habría borrado, en el ejemplar de trabajo, de la lista de sus publicaciones (i¿?!). ¿Existirá constancia por escrito de esa nueva actitud, positiva extrabibliográficamente/negativa científicamente, incluso con presentación de disculpas? En todo caso, la letra nunca muere...

${ }_{21}$ Previamente, en carta a Dámaso Alonso (Salamanca, 25-X-1958; «Legado Dámaso Alonso» en la Real Academia Española) anunciaba tales mejoras: «Estoy ya trabajando en la nueva edición del Diccionario. Aparte las correcciones y ampliaciones necesarias, voy a introducir algunas novedades; así, la terminología de Bloomfield y de su escuela; completaré los términos glosemáticos, los de crítica textual y los de retórica. Pienso añadir una copiosa enumeración de lenguas y dialectos, localizándolos. Duplicaré, por lo menos, el número de términos alemanes. Y deseo añadir, al final, una especie de concordancias, agrupando los términos que pertenecen a los mismos dominios de la Lingüística (términos fonéticos, fonológicos, morfológicos, sintácticos, etc.), que permitirán buscar el término partiendo del concepto». Y en la del 15 de abril de 1961: «Envié a Gredos, la semana pasada, la 2a ed. del Diccionario, con un tercio más de materia. A ver si se deciden a imprimirlo pronto».

22 En otra carta de F. Lázaro a Dámaso Alonso (Salamanca, 15 de abril de 1961), muestra su natural desagrado por la consabida reseña de Corominas; y lo hace con expresivas palabras que yo suscribiría plenamente. Luego continúa: «Por eso, he decidido replicarle. He escrito una contestación, que recibirá Vd., junto con algunas separatas, en este mismo correo. Celebraría mucho que, a no tener Vd. cualquier tipo de inconveniente, la leyera con algún cuidado, y me hiciese llegar sus observaciones, en la seguridad de que haría un uso archidiscreto de las mismas. Es que, antes de enviar a Thesaurus la réplica, desearía estar seguro de que 
Se trata de un texto objetivo, equilibrado, modelo de lo que debe ser una réplica científica, no personal, cuando de contestar a una crítica descarnada, no sé si incluso despiadada, se trata (nos hallamos en la que, para mí, es la época científicamente más fecunda y positiva del Dr. Lázaro Carreter). Los párrafos primero y último son de tipo general (introductorio y conclusivo: entre lo humano y lo técnico ambos); lo demás, ordenada y muy justa réplica, o mero comentario, a las observaciones de Corominas, reconociendo lo defendible de algunas de ellas y, al mismo tiempo, los diversos errores y las aseveraciones necesitadas de matices. De las dos fotocopias que yo poseía, hice llegar una a la persona más cercana posible - entre otras razones, por ser miembro nuclear de su familia además, de pertenecer al campo de la lingüística españolaal maestro Fernando Lázaro Carreter y, junto al envío, le sugería la conveniencia de que dicho texto viese la luz (editado por él mismo o, si no, por algún colega de su confianza), pero, desgraciadamente, ni se me informó de la recepción del texto por parte de su destinatario (¿se perdió en el correo?) ni ha aparecido publicado; y de haber visto la luz, por un elemental acto de justicia, las personas que se están formando en nuestro campo de estudio habrían podido aprender no pocas realidades del por mí considerado, cual señalé al principio de esta nota, un texto ejemplar. Dejo constancia de que, si la persona aludida me autoriza explícitamente, no pondré reparo alguno en ponerlo en letra de molde, preferiblemente junto al original texto de Corominas (naturalmente, si en este frente también se me diera luz verde para dicha operación), bien en sucesión mecánica, bien haciéndolos entrar en «diálogo temático lineal» con una determinada presentación en la macroestructura tipográfica.

\section{6}

Pues bien: me voy a permitir presentar una serie de informaciones y algún texto con la idea de crear el entorno adecuado para una mejor comprensión de los hechos implícitos en la consabida manifestación negativa con respecto a los materiales enviados por Maria Woitscheck. Comenzaré por dar noticia de los textos de los que yo poseo fotocopia (presumo que, sumando todo lo que se halle en el entorno de Corominas con lo de RMP, el conjunto podría ser considerablemente más amplio y daría tal vez para un volumen). Primero, 27 páginas (y en el dorso de la última, escrita una parte de ella) tamaño folio

\footnotetext{
la argumentación científica es irrebatible. Naturalmente, si por cualquier causa no quiere darme su parecer, sepa que, de antemano, comprendo sus motivos». Entiéndase: Corominas era, igualmente, autor, y nada secundario, en la Biblioteca Románica Hispánica de la editorial Gredos; no poseo datos en torno a si Dámaso Alonso contestó a dicha carta oralmente (por teléfono o en entrevista personal) o por escrito, caso este último que nos llevaría a consultar dicha posible respuesta en los materiales de archivo del Dr. Lázaro Carreter (si se hallasen algún día disponibles para los investigadores, vale decir, con acceso institucional). En situación, igualmente "aporética», no alejada de lo que aquí hemos narrado, véase su contundente y magistral texto «Réplica al profesor Entrambasaguas», en Revista de Archivos, Bibliotecas y Museos (Madrid), LXXVII-2/1974, págs. 773-782.
} 
de muy densa escritura mecanográfica (con incrustaciones manuscritas de formas griegas, etc., y dos diagramas) en alemán, todo relacionado con diversos análisis etimológicos; el más extenso (diez páginas y media) es el inicial, dedicado a comentar el trabajo de Henry y Renée KaHANE «Die Margariten», en Zeitschrift für romanische Philologie, LXXVI/3-4/1960, págs. 185-204. Todos esos textos delatan un esfuerzo notable, una actitud de disciplina metalingüística considerable: ni pueden ni deben ser despachados con una frase despectivamente ingeniosa, sino que un investigador serio debe agradecer la generosidad de la estudiosa Maria Woitscheck y entrar concienzudamente en esos textos; en el peor de los casos, algo provechoso podría sacar de ellos.

7

Tenemos además el material epistolar, a saber: 1) en el anverso de la última página se halla, manuscrita, una carta dirigida a Américo Castro, quizá para que Menéndez Pidal se la hiciera llegar, o bien fotocopia, adherida (i?), de la que le había enviado al discípulo de R. M. P.; 2) de cartas dirigidas al maestro de maestros por antonomasia, contamos con una primera, mecanografiada ( 9 de octubre de 1962) y, al parecer, dos manuscritas - la borrosa fotocopia no me permite discernir si se trata de una, de dos o incluso de tres-, la primera de gran amplitud y todo ello con los espacios escriturarios muy bien aprovechados, lo que, unido a una calidad no óptima de la fotocopia, a veces dificulta su lectura. Aunque la primera dirigida a RMP es, igualmente, muy extensa, dado que es, en principio, la única legible por hallarse mecanografiada, me iba a permitir reproducirla, pues en ella aparecen bellos recuerdos de su estancia en España en 1926 y de respeto y admiración por sus profesores o conferenciantes durante su estancia: Ortega (José Ortega y Gasset, 1883-1955), Zubiri (José Xavier Zubiri Apalategui, 1898-1983), Morente (Manuel García Morente, 1886-1942), Ovejero (Andrés Ovejero Bustamante, 1871-1954), Fagoaga (Lucio Gil Fagoaga, 1896-1989), Américo Castro (1885-1972), Tomás Navarro Tomás (1884-1979), Alonso (¿Dámaso, 1898-1990, Amado, 1896-1952, ambos?); finalmente he renunciado a ello, pues la fotocopia deja varios segmentos textuales algo desleídos y resultaría más bien arriesgado interpretar desde una percepción insegura.

8

En cambio, lo que sí puedo reproducir, de una copia mecanografiada con dos líneas manuscritas al final del segundo párrafo, es la contestación de Menéndez Pidal (carta ácrona, pero, conociendo los hábitos de cortesía del maestro, de octubre de 1962):

Muy distinguida Sra. mía: Mucho he agradecido su carta y el envío de su trabajo exponiendo su punto de vista con relación al [tachado /trabajo sobre/] «Margarites» ${ }^{23}$ de Henry y Renée Kahane. En estos momentos

${ }^{23}$ En el enunciado del texto mecanografiado de M. Woitscheck, «Stellungnahme zu der Abhandlung "Magarites" von Henry und Renée KAHANE in der [...]»: R.M.P. ya había recibido 
estoy abrumado de trabajo corrigiendo las pruebas de un libro sobre el P. Las Casas [El padre Las Casas. Su doble personalidad, Espasa-Calpe, Madrid, 1963], pero cuando pase este apuro espero poder leer su trabajo con el detenimiento que se merece y se lo enviaré después a Corominas, como Vd. desea.

Veo que ha conservado Vd. buenos recuerdos de su estancia en Madrid y de toda la gente que tuvo ocasión de tratar aquí, especialmente en el Centro de Estudios Históricos. Muchos de ellos han desaparecido ya como Morente y Ovejero. Otros como Zubiri han cambiado incluso de estado. Este obtuvo de Roma la anulación de su estado sacerdotal y se casó con Carmen Castro [1912-1997], la hija de Américo. Castro vive ahora en América, aunque pasa aquí cortas temporadas de vez en cuando. Le remitiré uno de estos días su trabajo, como Vd. desea [ahora viene la adición manuscrita]. El marqués de Pidal que Vd. conoció aquí sería Alfonso Pidal[,] a quien traté bastante. Ya ha muerto también y con sus hijos no continúo relación [véase la unidad siguiente, 9]. Ya ve Vd. cuánta gente ve desaparecer un hombre de 93 años como yo.

Repitiéndole el agrado que he tenido de recibir noticias de una alumna tan antigua y deseando siga Vd, interesándose por la filología[,] queda suyo con muy cordiales saludos [...].

He consultado enciclopedias varias para indagar acerca de las fechas de nacimiento y deceso del personaje acabado de mencionar, el Marqués de Pidal, pero el resultado ha sido infructuoso; incluso he recurrido a la vía informática. Más todavía: en alguna de las informaciones obtenidas se decía que había sido miembro de la Real Academia Española, pero no constaba en la obra de Alonso ZAMORA Vicente Historia de la Real Academia Española, Espasa-Calpe, Madrid, 1999 (dato de última hora: 22015 , Real Academia Española y Fundación María Cristina Masaveu Peterson, Madrid, con objetable cambio de título, en lo que no puedo detenerme ahora; sendos prólogos de Darío Villanueva y Fernando Masaveu; documentalista: Mario Pedrazuela Fuentes). Finalmente, me dirigí a doña Ma Elvira Fernández del Pozo, responsable del archivo de la RAE, que amablemente, y con rapidez, me comunicó lo siguiente (15 de febrero, 2013): «Don Alfonso Pidal y Chico de Guzmán no ha sido miembro de esta Corporación. Es hijo de Luis Pidal y Mon y, por lo tanto, tercer marqués de Pidal. Fue Caballero de la Orden de Santiago y se casó con Adelaida Fernández-Hontoria, creo que en San Jerónimo el Real, el 24 de octubre de 1910. El expediente de pruebas para el ingreso en la Orden de Santiago se conserva en el Archivo Histórico Nacional [...]; en él podrá encontrar parte de su filiación (lugar de nacimiento, partida de bautismo...

separata de dicho trabajo (aunque en ella no se perciben anotaciones de lectura como en otras ocasiones) con la dedicatoria «Con afectuosos saludos». Los otros datos de la ficha son: «Die Margariten», en Zeitschrift für romanische Philologie, LXXVI /3-4/ 1960, págs. 185-204. No puedo detenerme en la explanación de variantes. 
y otros datos biográficos que le pueden interesar) y en la parroquiade los Jerónimos, en los libros de matrimonio, también.ll Con la esperanza de que estos datos puedan ayudarle en su investigación, le envía un cordial saludo [...]. Enseguida hice la consulta en el consabido AHN; amablemente, doña Esperanza Adrados Villar, Jefe del Departamento de Referencias, me comunica (28 de febrero, 2013): «[...] se ha obtenido la siguiente información de su interés: fecha de nacimiento, 29 de septiembre de 1887. No aparece fecha de defunción [...]». Finalmente, dando por muy probable que en el diario madrileño $A b c$, sección OBITUARIOS, aparecería el dato que me faltaba, el año de defunción, me dirigí a dicho periódico; con gran eficacia, doña Sara García Monge, Departamento de Archivo y Documentación, me escribe (5 de marzo, 2013): «En relación con su petición, adjunto le remitimos la página de $\mathrm{ABC}$ en donde se recoge la noticia de su fallecimiento, localizada a través de nuestra hemeroteca online, /http://hemeroteca.abc.es/[...]». En efecto, en la edición de Andalucía, 14 de julio de 1954, pág. 32, tercera columna, bajo NECROLÓGICAS y el titular en negrita El marqués de Pidal, y precediendo al texto /Torrelavega [antaño, provincia de Santander, dentro de Castilla La Vieja; hoy, Comunidad Autónoma Uniprovincial de Cantabria], 13/, podemos leer: «En su finca veraniega de esta ciudad, ha fallecido, esta mañana, don Alfonso Pidal y Chico de Guzmán, [tercer] marqués de Pidal, que gozaba de mucho prestigio en las altas esferas de las finanzas, industria y economía nacional» (Agencia EFE). Vemos, pues, el camino alargado, como la sombra del ciprés, hasta la consecución de esos escurridizos datos «bianuales». 